\title{
Novel Ecogenic Plasmonic Biohybrids as Multifunctional Bioactive Coatings
}

\author{
Marcela Elisabeta Barbinta-Patrascu ${ }^{1}$, Camelia Ungureanu ${ }^{2, *}$, Nicoleta Badea ${ }^{2}$, \\ Mihaela Bacalum ${ }^{3}{ }^{(D}$, Andrada Lazea-Stoyanova ${ }^{4}$, Irina Zgura ${ }^{5}$ (D), Catalin Negrila ${ }^{5}$, \\ Monica Enculescu ${ }^{5}$ iD and Cristian Burnei ${ }^{6}$
}

1 Department of Electricity, Solid-State Physics and Biophysics, Faculty of Physics, University of Bucharest, 405 Atomistilor Street, PO Box MG-11, 077125 Magurele, Romania; elipatras@gmail.com

2 General Chemistry Department, University Politehnica of Bucharest, 313 Splaiul Independentei, 060042 Bucharest, Romania; nicoleta.badea@gmail.com

3 Department of Life and Environmental Physics, Horia Hulubei National Institute for Physics and Nuclear Engineering (IFIN-HH), 077125 Magurele, Romania; bmihaela@nipne.ro

4 Department of Low Temperature Plasma Department, National Institute for Lasers, Plasma and Radiation Physics, 409 Atomistilor Str., 077125 Magurele, Romania; andrada@infim.ro

5 Optical Processes in Nanostructured Materials Laboratory, Nanoscale Condensed Matter Laboratory, Multifunctional Materials and Structures Laboratory, National Institute of Materials Physics, Atomistilor 405A, 077125 Magurele, Romania; irina.zgura@infim.ro (I.Z.); catalin.negrila@infim.ro (C.N.); mdatcu@infim.ro (M.E.)

6 Clinical Emergency Hospital, Calea Floreasca 8, 014461 Bucharest, Romania; burneicristian@yahoo.com

* Correspondence: camelia.ungureanu@upb.ro; Tel.: +4-0723-239-120

Received: 30 May 2020; Accepted: 7 July 2020; Published: 9 July 2020

\begin{abstract}
The objective of the present study is the valorization of natural resources and the recycling of vegetal wastes by converting them into novel plasmonic bio-active hybrids. Thus, a "green" approach was used to design pectin-coated bio-nanosilver. Silver nanoparticles were generated from two common garden herbs (Mentha piperita and Amaranthus retroflexus), and pectin was extracted from lemon peels. The samples were characterized by the following methods: Ultraviolet-visible (UV-Vis) absorption spectroscopy, Fourier Transform Infrared (FT-IR), X-ray Diffraction (XRD), X-ray Photoelectron Spectroscopy (XPS), dynamic light scattering (DLS), Atomic Force Microscopy (AFM), Scanning Electron Microscopy (SEM)-Energy-dispersive X-ray Spectroscopy (EDX), and zeta potential measurements. Microscopic investigations revealed the spherical shape and the nano-scale size of the prepared biohybrids. Their bioperformances were checked in terms of antioxidant and antibacterial activity. The developed plasmonic materials exhibited a strong ability to scavenge short-life $(96.1 \% \div 98.7 \%)$ and long-life $(39.1 \% \div 91 \%)$ free radicals. Microbiological analyses demonstrated an impressive antibacterial effectiveness of pectin-based hybrids against Escherichia coli. The results are promising, and the obtained biomaterials could be used in many bio-applications, especially as antioxidant and antimicrobial biocoatings.
\end{abstract}

Keywords: silver nanoparticles; garden herbs; pectin; “green” design; bioperformances

\section{Introduction}

The idea to use the plants in biomaterial design is an exciting trend nowadays. Local herbs, weeds, and vegetal wastes (e.g., Citrus peels) [1] could be valorized by using "green" approaches to obtain valuable products such as bio-multifunctional coatings. The application of phytosynthesized metal nanoparticles for the development of antimicrobial coatings has gained an increasing importance in the last few decades, representing a good alternative to remove hazardous reagents [2]. Silver nanoparticles 
(AgNPs) have received attention from researchers in the twenty-first century for their unique properties and different applications in medicine: drug delivery, bioimaging and optoelectronics. The alternative green approaches for AgNP synthesis, by using the wide bioreducing potential of the plant kingdom, are bio-friendly and non-expensive, being in the spotlight of international interest due to their great ecological importance based on the valorization of natural resources and recycling vegetal wastes by converting them into novel plasmonic materials with interesting properties [3-6].

During phytosynthesis, the metal ions are reduced by aqueous plant extracts which act both as reducing and capping agents, resulting in metallic nanoparticles (MNPs) carrying antioxidant and antimicrobial phyto-molecules [3,5].

On the other hand, in the last few years, there has been an increased interest in the "green" design of biocompatible coating film for applications in the biomedical field or in the food industry. Polysaccharides, like pectin, have been used as one of the main raw materials for obtaining edible coatings, due to their natural abundance, low cost and renewable feature, and the incorporation of active compounds into such edible films and coatings resulted in an effective antibacterial effect and the enhancing of the antioxidant activity [7]. Pectin has also been employed to prepare antimicrobial biopolymeric materials in the food and biomedical fields [8].

Recent studies pointed out the use of pectin as one of the most important materials in preparation of polysaccharide-based edible coatings in reducing some problems associated with the loss of quality of fresh-cut Cucumis melo [9], and Citrus aurantifolium [10], improving product safety for consumers, in an edible package with no plastic waste for disposal.

Moreover, pectin is considered as "a miracle biopolymer" because of its excellent biocompatibility and biodegradablility, features that are exploited in food industries and in biomedical applications [11].

Most researchers reported the use of biopolymer pectin to "green" synthesis silver nanoparticles. Thus, pectin from apple peel was used to obtain AgNPs with antibacterial properties against Escherichia coli; in this case, pectin acted both as reducing and coating agent [12]. Balachandran et al. [12] compared antibacterial activity of AgNPs synthesized using Azadirachta indica leaves with AgNPs synthesized using apple pectin, and they found that both types of AgNPs showed almost similar level of bactericidal activity.

This study reports for the first time, the design of novel ecogenic plasmonic biohybrids containing pectin (from fresh lemon peels) and silver nanoparticles (AgNPs) "green" synthesized from natural aqueous extracts of Mentha piperita and Amaranthus retroflexus leaves. In our present study, the vegetal extracts acted both as bioreducing and capping agents, in the AgNPs phytosynthesis. The natural polymer pectin was then added to the "green" obtained AgNPs, to develop multifunctional bioactive nano-entities.

Reducing the huge amount of vegetal wastes is an important issue nowadays, due to their possible deleterious effects; for example, Citrus peels generated in large amounts every year during food industry could be harmful for ruminants and can cause soil salinity [13], and their efficient valorization is an interesting challenge to develop new materials with unusual properties. Citrus peels are rich in bio-ingredients such as vitamin $\mathrm{C}$ and phenolic compounds (like hesperidin, narirutin and naringin) with antioxidant activity [14].

Plants such as Mentha piperita and Amaranthus retroflexus are valuable reservoirs of bio-active constituents with antioxidant and antimicrobial properties, and that is why they were chosen in our investigations. For instance, Mentha piperita L. or peppermint, or mint, is an aromatic herb, rich in rosmarinic acid, eriocitrin and, hesperidinin with antimicrobial, antioxidant, anti-inflammatory, and antiallergic properties [15]. On the other hand, Amaranthus retroflexus or "pigweed" has long been used for food and medicinal purposes [16]. 
The biofabrication of pectin-bio-nanosilver composites were investigated by various spectroscopic methods: Ultraviolet-visible (UV-Vis) absorption and Fourier Transform Infrared (FT-IR) spectroscopy, Dynamic Light Scattering (DLS), and microscopic techniques: Atomic Force Microscopy (AFM), Scanning Electron Microscopy (SEM), and also by zeta potential (measurements. The structural investigation of developed materials was performed through X-Ray Diffraction (XRD) technique, and the elemental compositional analysis of was investigated by X-ray photoelectron spectroscopy (XPS) and by Energy-dispersive X-ray spectroscopy (EDX). Furthermore, the bio-properties of developed materials were checked in terms of antioxidant (chemiluminescence and 2,2azinobis-(3-ethylbenzthiazoline-6-sulfonic acid) (ABTS) assay) and antibacterial (in vitro tested against Escherichia coli) activity.

\section{Materials and Methods}

\subsection{Materials}

Silver nitrate $\left(\mathrm{AgNO}_{3}\right)$, peptone, Tris (hydroxymethylaminomethane base), $\mathrm{HCl}, \mathrm{H}_{2} \mathrm{O}_{2}$, luminol (5-amino-2, 3-dihydro-phthalazine-1, 4-dione), were purchased from Merck (Darmstadt, Germany). Soybean lecithin, $\mathrm{NaCl}$, Trolox (6-hydroxy-2,5,7,8-tetramethylchroman-2-carboxylic acid), 2,2azinobis-(3-ethylbenzthiazoline-6-sulfonic acid) (ABTS) and potassium persulfate from Sigma Aldrich (Saint-Louis, MO, USA). Agar was purchased from Fluka (Bucharest, Romania) and the yeast extract was obtained from Biolife Fluka (Bucharest, Romania). The herbs (Mentha piperita and Amaranthus retroflexus) were collected from the Dărăști-Vlașca area, Giurgiu County $\left(44^{\circ} 17^{\prime} 30^{\prime \prime} \mathrm{N}\right.$ $\left.26^{\circ} 0^{\prime} 34^{\prime \prime} \mathrm{E}\right)$, from one of the authors' private gardens, and the lemons were purchased from a local market.

\subsection{Biosynthesis of Ecogenic Plasmonic Biohybrids}

The preparation of phyto-generated plasmonic biohybrids included two main stages:

\subsubsection{Preparation of Phytogenic Silver Nanoparticles}

Silver nanoparticles were generated from two common garden herbs (mint and pigweed), by following the steps:

a. Preparation of vegetal extracts. Fresh leaves of garden herbs: Mentha piperita and Amaranthus retroflexus washed in distilled water were chopped and immersed in hot distilled water (in a mass ratio of vegetal material: water of 1:5), and then boiled for $15 \mathrm{~min}$. The extracts were then filtered through Whatman filter papers No. 1 and stored at $-20^{\circ} \mathrm{C}$ until their use [17].

b. Phyto-synthesis of silver nanoparticles was achieved by an economical and environmentally friendly process that involves mixing a volume of $1 \mathrm{mM} \mathrm{AgNO}_{3}$ aqueous solution with an equal volume of plant extracts, under continuous magnetic stirring, as described in [17].

\subsubsection{Preparation of Ecogenic Plasmonic Biohybrids}

The pectin coating was prepared from fresh lemon peels based on the procedure described in [18]. The pectin-coated phytogenic silver nanoparticles were achieved by mixing equal volumes of pectin and AgNPs, under continuous stirring. Then, these biocomposites were further subjected to ultrasonic irradiation (5 min, on ultrasound bath Elmasonic $\mathrm{S} 60 \mathrm{H}$ Elma Schmidbauer $\mathrm{GmbH}$, Singen, Germany).

The sample descriptions and their corresponding codes is shown in Table 1, and the schematic representation of the preparation of ecogenic plasmonic biohybrids is displayed in Figure 1. 
Table 1. Sample descriptions and their corresponding codes.

\begin{tabular}{ccc}
\hline No. & Sample Description & Sample Code \\
\hline 1 & Vegetal aqueous extract from leaves of mint (Mentha piperita) & MNT \\
2 & Vegetal aqueous extract from leaves of pigweed \\
3 & (Amaranthus retroflexus) & AMT \\
4 & AgNPs phyto synthesized from vegetal aqueous extract from leaves & PCT \\
& of mint (Mentha piperita) & MNT-nAg \\
5 & AgNPs phyto synthesized from vegetal aqueous extract from leaves & \\
6 & of pigweed (Amaranthus retroflexus) & AMT-nAg \\
7 & Biohybrid generated from MNT-nAg and pectin & MNT-nAg-PCT \\
& Biohybrid generated from AMT-nAg and pectin & AMT-nAg-PCT \\
\hline
\end{tabular}

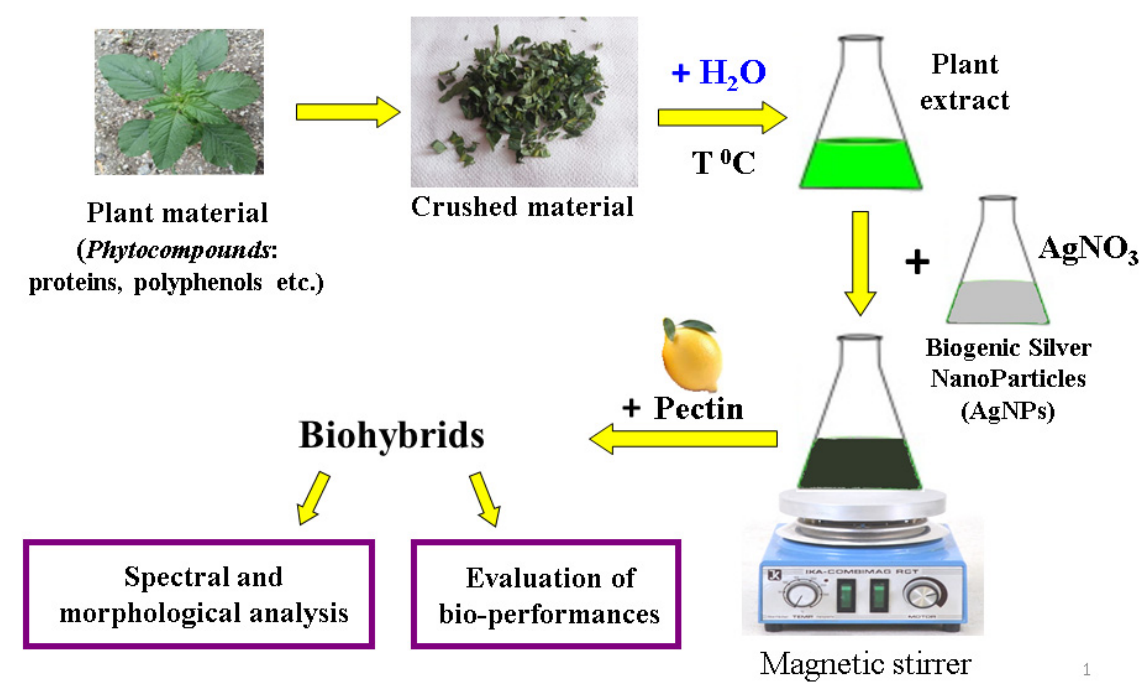

Figure 1. Schematic representation of phyto-generation of silver nanoparticles and preparation of pectin-coated bio-nanosilver.

\subsection{Physico-Chemical and Biological Characterization of Developed Biohybrids}

\subsubsection{Spectral, Structural, and Morphological Analysis}

The UV-Vis absorption spectra of the silver-based samples were recorded (at the resolution of $1 \mathrm{~nm}$ ) on a double beam UV-Vis-NIR Spectrophotomer V670, Jasco, Tokyo, Japan, from 200 to $800 \mathrm{~nm}$.

Fourier transform infrared (FT-IR) spectroscopy study was conducted with PerkinElmer-Spectrum 100 spectrometer (Waltham, Massachusetts, MA, USA); The spectra were recorded between 4000 and $500 \mathrm{~cm}^{-1}$, with a resolution of $4 \mathrm{~cm}^{-1}$ and a total of $56 \mathrm{scans} /$ measurement. The samples were deposited on $\mathrm{Si}$ (100) for FT-IR characterizations by the drop cast method, and the removal of the liquid matrix was performed by vacuum evaporation at room temperature in Vacuum oven, BMT Vacucell $22 \mathrm{~L}$ (Planegg/München, Germany) assisted by a Dry Oil-Free Scroll Vacuum Pump, Agilent Varian SH-110 (Lexington, Massachusetts, MA, USA);

The crystallinity of the samples was identified by X-ray diffraction (XRD) using a Bruker D8 Advance diffractometer (Billerica, Massachusetts, MA, USA) with CuK $\alpha$ radiation $(\lambda=0.154 \mathrm{~nm})$; the $K \beta$ radiation was eliminated by using a nickel filter. Diffraction patterns were recorded at room temperature in Bragg-Brentano geometry from $15^{\circ}$ to $80^{\circ}$ (the range of $2 \theta$ ) at a speed of $0.8^{\circ} / \mathrm{min}$ (20/min). The XRD data were processed using "Bruker Diffrac plus Basic Package Evaluation v.12". For XRD measurements the samples were deposited on a zero-diffraction plate by drop cast method at the room temperature, obtaining a solid film, using the same vacuum oven, like the case of FTIR investigations. 
The X-ray photoelectron spectroscopy (XPS) measurements were performed using a SPECS photoelectron spectrometer with a PHOIBOS 150 analyzer (Berlin, Germany) in order to highlight the chemical states of the components. The X-ray source, XR-50 (PHOIBOS, Berlin, Germany) operates on an $\mathrm{Mg}$ anode $(\mathrm{h} v=1253.6 \mathrm{eV})$ at $300 \mathrm{~W}, 24 \mathrm{~mA}$ and $12.5 \mathrm{kV}$. The acquisition was made with pass energy of $10 \mathrm{eV}$ for individual spectrum and $50 \mathrm{eV}$ for extended spectrum. The fitting of the spectra was undertaken in the Spectral Data Processor software using Voigt functions and specific sensitivity factors.

Zeta potential $(\xi, \mathrm{mV})$ measurements were performed in triplicate, at $25^{\circ} \mathrm{C}$, with a special device of Zetasizer Nano ZS (Malvern Instruments Ltd., Worcestershire, UK) by applying an electric field across the tested aqueous suspensions. The mean values of $\xi$ were reported.

Dynamic Light Scattering (DLS) method was used to evaluate the average size, $Z_{\text {ave }}$, as hydrodynamic diameter of the particles (the particle diameter plus the double-layer thickness), and also the polydispersity index, $\mathrm{PdI}$ (which is an indicative of uniformity of particle population). The samples were analyzed on Zetasizer Nano ZS (Malvern Instruments Ltd., Worcestershire, UK), as previously described [19]. The mean values \pm standard deviations of $Z_{\text {ave }}$ and PdI were reported for each sample, from three individual measurements.

For achieving more information about size and morphological aspects, the samples were characterized by Atomic Force Microscopic (AFM) analyses which were carried out using a NanoWizard 4 BioScience AFM (JPK instruments AG, Berlin, Germany). A volume of $10 \mu \mathrm{L}$ of the nanoparticles stock solution was pipetted on mica sheets and dried before performing the measurements in air. The intermittent contact mode was used to obtain the images.

To obtain a deep insight about the surface morphology, the samples were also analyzed using a scanning electron microscope (SEM), a FEI Inspect S50 apparatus (Hillsboro, OR, USA. The secondary electrons (SE) images were acquired for a $10 \mathrm{~mm}$ working distance, magnifications were varied between 50 and 50,000 x and acceleration voltages of $2-10 \mathrm{kV}$ were used. Before any imaging, a $5 \mathrm{~nm} \mathrm{Au}$ thin film was placed on the sample's surface using a Cressington 108 auto sputter coater apparatus, equipped with a Cressington $\mathrm{mtm} 20$ thickness controller.

A Gemini 500 Carl Zeiss scanning electron microscope (SEM) equipped with a QUANTAX 200 energy-dispersive X-ray spectrometer (Bruker Nano GmbH, Berlin, Germany) (EDX) with XFlash ${ }^{\circledR} 6$ silicon drift detector(SDD), energy resolution $<129 \mathrm{eV}$ at Mn-K alpha and Peltier cooling, was used to investigate the morphology and elemental composition of the samples.

\subsubsection{Biological Characterization of Developed Biohybrid Materials}

(i) In vitro determination of antioxidant action, evaluation by chemiluminescence and TEAC assays

Chemiluminescence method. The in vitro determination of antioxidant behavior of AgNPs/biohybrids by means their ability to scavenge the oxygen free radicals (ROS) was achieved by chemiluminescence assay. The chemiluminescence system used was contained luminol and hydrogen peroxide $\left(\mathrm{H}_{2} \mathrm{O}_{2}\right)$ in Tris- $\mathrm{HCl}$ buffer solution at $\mathrm{pH}$ 8.6, by using a Chemiluminometer (TD 20/20, Turner Designs, Inc., Sunnyvale, CA, USA) [20]. The antioxidant activity ( $\% A A)$ of AgNPs/ biohybrids was calculated by the following relation:

$$
\% A A=\frac{I_{0}-I_{S}}{I_{0}} \cdot 100
$$

where $I_{\mathrm{S}}$ and $I_{0}$ are the maximum chemiluminescence for standard and for the sample, at $\mathrm{t}=5 \mathrm{~s}$.

ABTS assay. The capacity of AgNPs/ biohybrids to scavenge $\mathrm{ABTS}^{\bullet+}$ radical was spectral evaluated by monitoring the absorbance at $734 \mathrm{~nm}$. The long-life radical ABTS ${ }^{\bullet+}$ was obtained after reaction between $7 \mathrm{mM}$ ABTS solution and $2.45 \mathrm{mM}$ potassium persulfate solution. After $16 \mathrm{~h}$, this solution was normalized at $734 \mathrm{~nm}$ to an absorbance of $0.70( \pm 0.02)$ using an UV-Vis-NIR 
Spectrophotomer (V670, Jasco, Tokyo, Japan). The inhibition of $\mathrm{ABTS}^{\bullet+}$ cation radical (\%) was calculated using the following equation:

$$
\% \text { Inhibition } \mathrm{ABTS}^{\bullet+}=\frac{A_{0}-A_{S}}{A_{0}} \cdot 100
$$

where:

- $A_{0}$ is the absorbance of the blank ( $3 \mathrm{~mL}$ of $\mathrm{ABTS}^{\bullet+}$ diluted solution and $2 \mathrm{~mL}$ of distilled water);

- $A_{\mathrm{s}}$ is the absorbance of the samples ( $3 \mathrm{~mL} \mathrm{ABTS}^{\bullet+}$ diluted solution, $1 \mathrm{~mL}$ AgNPs/ biohybrids +1 $\mathrm{mL}$ of distilled water).

(ii) Antibacterial activity assessment of silver-based coatings

For the antibacterial assay, the samples were tested against Escherichia coli ATCC 8738 bacterium. Escherichia coli was grown in Luria Bertani Agar (LBA) plates at $37^{\circ} \mathrm{C}$ [21]. LBA contains the following substances: peptone (Merck), $10 \mathrm{~g} / \mathrm{L}$; yeast extract (Biolife) $5 \mathrm{~g} / \mathrm{L}, \mathrm{NaCl}$ (Sigma-Aldrich) $5 \mathrm{~g} / \mathrm{L}$ and agar (Fluka) $20 \mathrm{~g} / \mathrm{L}$. The stock culture was kept in the fridge at $4{ }^{\circ} \mathrm{C}$.

For determination of minimum bactericidal concentration (MBC) of AgNPs against Escherichia coli we used broth dilution technique [22]. Briefly, serially diluted logarithmic concentrations of the AgNPs ranging from 400 to $0.195 \mu \mathrm{g} / \mathrm{mL}$ were inoculated with Escherichia coli and maintained at $37^{\circ} \mathrm{C}$, for $18 \mathrm{~h}$. [23].

Antibacterial activity of developed materials against test bacteria was evaluated by both qualitative and quantitative methods:

a. Qualitative assessment by agar well diffusion method [24,25].

The entire Petri dish surface is inoculated by spreading a volume of the Escherichia coli bacterium. Then, a well with a diameter of $6 \mathrm{~mm}$ is punched aseptically and a volume $50 \mu \mathrm{L}$ of the extract solution is introduced into the well. Then, Petri dishes are incubated at $37^{\circ} \mathrm{C}$ for $24 \mathrm{~h}$. The antimicrobial agent diffuses into the agar and inhibits growth of bacterium and then the presence of a clear zone of inhibition (ZI) indicates the antimicrobial effectiveness of the samples.

b. Quantitative assessment by percentage reduction test [26].

The initial concentration of Escherichia coli was adjusted to $10^{-9}$ colony forming units (CFUs)/mL. A volume of $5 \mu \mathrm{L}$ of microbial suspension was transferred onto $50 \mu \mathrm{L}$ of sample. After $3 \mathrm{~h}$, the solution was pipetted to a $10 \mathrm{~mL}$ of sterile water, and then fully vibrated to harvest the cells. An amount of $0.1 \mathrm{~mL}$ of each rinse was placed onto LBA plates. The efficiency of the antibacterial test was determined by comparing the reduction in Escherichia coli concentration of the samples with that of control expressed as a percentage reduction in standard time. The Petri dishes was incubated for $18 \mathrm{~h}$ at $37^{\circ} \mathrm{C}$ to determine the CFUs [27]. The bactericidal ratio ( $\mathrm{R}, \%$, the antimicrobial effect of each group) was calculated as follows:

$$
\mathrm{R}(\%)=\frac{\mathrm{CFU}_{\text {controlgroup }}-\mathrm{CFU}_{\text {exp erimentalgroup }}}{\mathrm{CFU}} \cdot 100
$$

The nanoparticle susceptibility constant $Z(\mathrm{~mL} / \mu \mathrm{g})$ is defined by the following equation [28]:

$$
Z=\frac{-\ln \left(N / N_{0}\right)}{C}
$$

where $N$ is the bacterial colony forming units on the agar plate containing nanoparticles, $N_{0}$ is the CFUs on the pure agar plate, and $C$ is the concentration of nanoparticles $(\mu \mathrm{g} / \mathrm{mL})$.

Using the $Z$ value and a given $C$ value, the survival fraction $\left(N / N_{0}\right)$ can be determined.

A higher $Z$ value shows that the microorganisms are more sensitive to the samples, signifying that the materials are very toxic to the bacteria. 
In these experiments, blank solvent (water) was employed as negative control in all sample analyses.

Statistical analysis. All experiments were carried out in triplicate, and the obtained data were analyzed for statistical significance using $t$-test to determine significant differences among means. Significant differences were set at $p \leq 0.05$ (relationship between datasets) and were computed using the Excel (Microsoft Office 365) $t$-test from the data analysis tool pack. The results presented represent the Mean \pm standard error of mean of independent replicates.

\section{Results}

\subsection{Optical Characterization}

The new, obtained materials were optically characterized by UV-V is absorption and FT-IR spectroscopy, to obtain valuable information regarding the interaction between building blocks of pectin-based biohybrids, and about the formation of these biohybrids.

"Green" bio-assisted synthesis of silver nanoparticles (using two garden herbs: mint and amaranth) and the formation of pectin-based hybrids were firstly monitored by UV-Vis absorption spectroscopy (Figure 2).

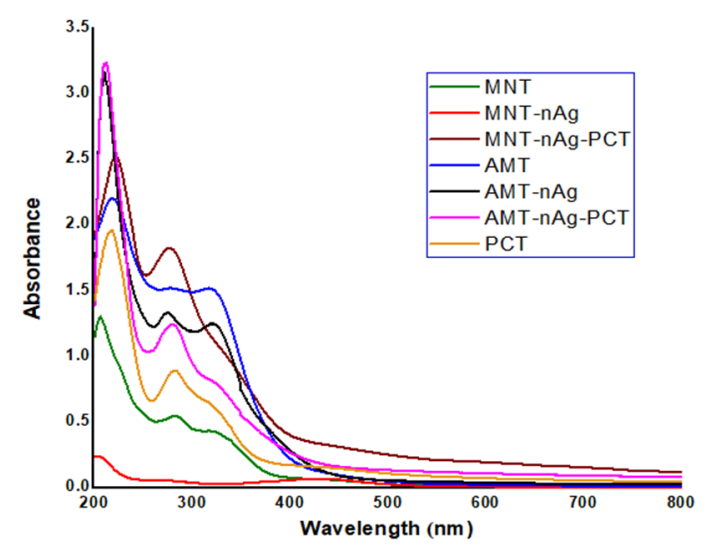

(a)

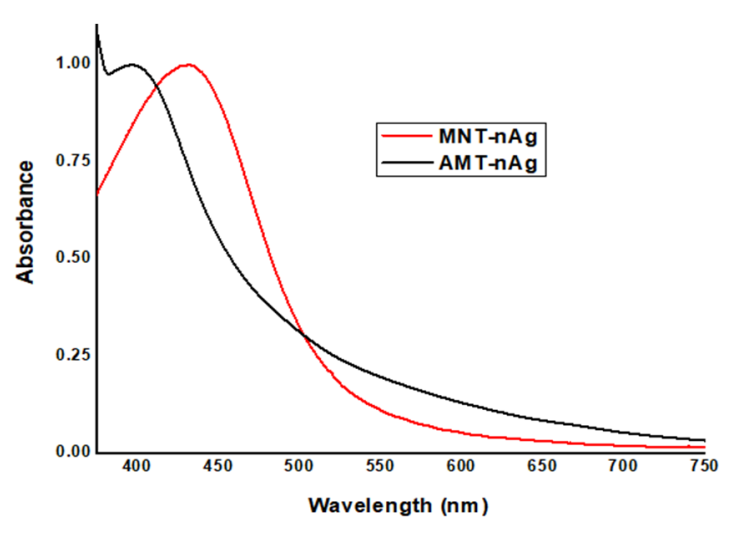

(b)

Figure 2. Ultraviolet-visible (UV-Vis) absorption spectra of phytogenic silver nanoparticles and of pectin-coated entities, developed in this study. (a) Comparative presentation of UV-Vis absorption spectra of the obtained samples; (b) SPR (Surface Plasmon Resonance) bands of "green" synthesized silver nanoparticles (AgNPs).

The absorption spectra of the obtained samples, displayed comparatively in Figure 2a, showed different absorption peaks: between 205-221 nm —assigned to the carbohydrates [13,29-31], and peptide bonds in proteins; between $274-279 \mathrm{~nm}$-attributed to the aromatic amino acid residues of proteins (tyrosine, tryptophan) and to the carbohydrates [13,29-31]; between 317-323 nm-assigned to the B ring portion (cinnamoyl system, band I) of flavonoids [32].

The phyto-mediated synthesis of MNT-nAg and of AMT-nAg was confirmed by the apparition of a single SPR (Surface Plasmon Resonance) band located at $435 \mathrm{~nm}$ and at $397 \mathrm{~nm}$, respectively, as shown in Figure 2b.

The bioreduction of silver ions and the formation of pectin-coated AgNPs were further investigated by FT-IR spectroscopy. Figure 3 shows the FT-IR spectra of lemon pectin (Figure 3a), and of developed materials phyto-generated from Mentha piperita (Figure 3b) and Amaranthus retroflexus (Figure 3c). In Table 2 are displayed the assignment of the main FT-IR bands for plant - derived materials developed in this research work. 


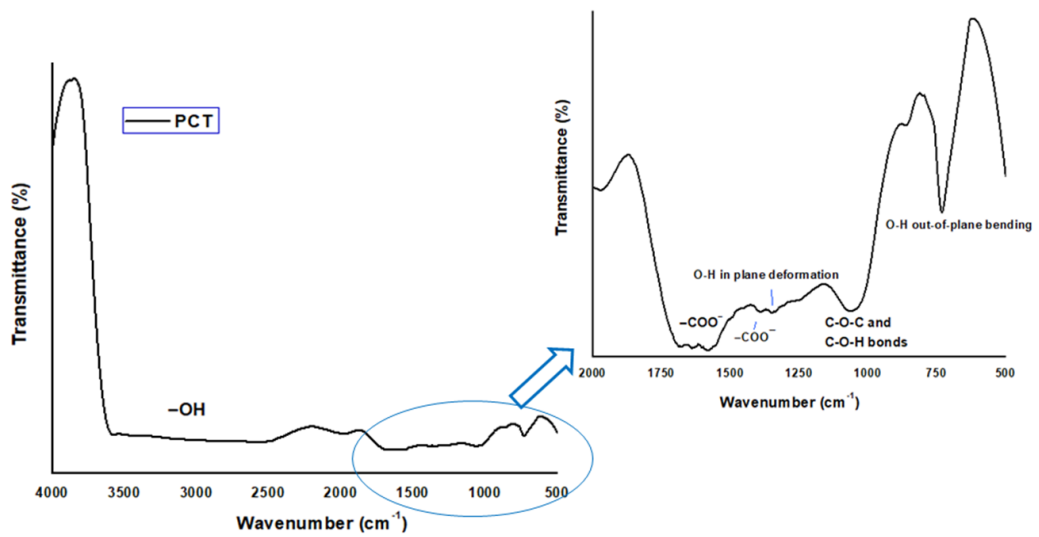

(a)

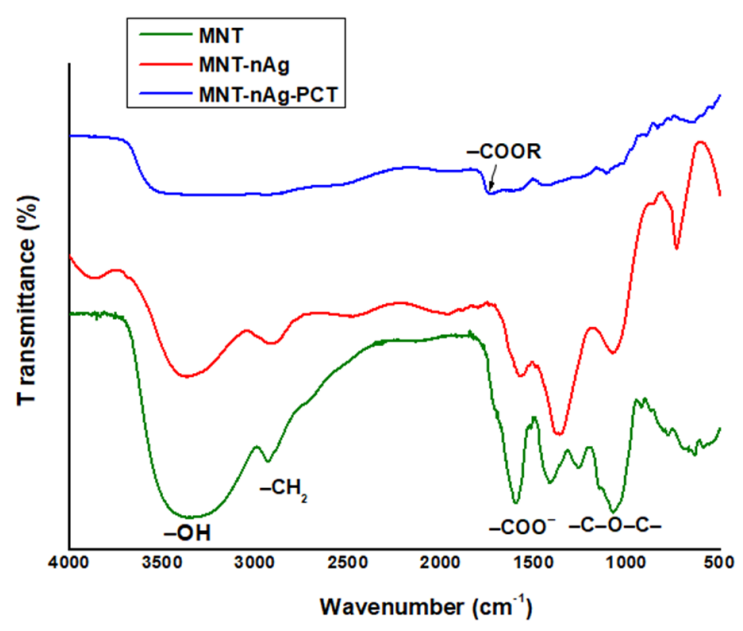

(b)

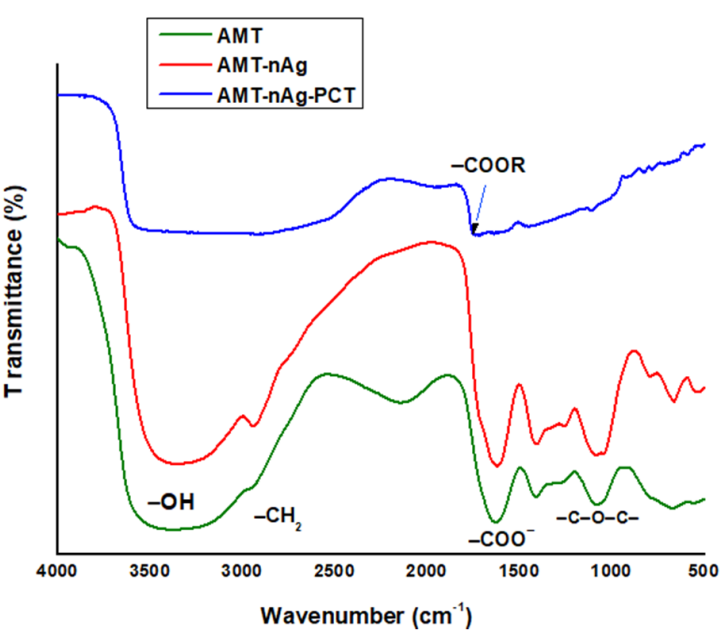

(c)

Figure 3. Fourier Transform Infrared (FT-IR) spectra of lemon pectin (a); and of materials generated from Mentha piperita (b) and Amaranthus retroflexus (c).

Table 2. FT-IR bands assignment for plant-derived materials developed in this study.

\begin{tabular}{|c|c|c|c|}
\hline $\begin{array}{l}\text { Sample } \\
\text { Code }\end{array}$ & FT-IR Bands $\left(\mathrm{cm}^{-1}\right)$ & Assignment & Ref. \\
\hline \multirow{4}{*}{ MNT/AMT } & $\begin{array}{c}3355 / 3391 \\
\text { (intense, broad band) }\end{array}$ & $\begin{array}{l}\text { Bending and stretching vibrations of } \\
\text { hydroxyl groups in polysaccharides, } \\
\text { alcohols, and phenolic compounds and } \\
\text { to N-H stretching vibrations }\end{array}$ & [3] \\
\hline & $2925 / 2949$ & $\mathrm{C}-\mathrm{H}$ stretching vibration & [33] \\
\hline & $1611 / 1630$ & $\begin{array}{l}\text { Amide I, arising due to carbonyl stretch } \\
\text { in proteins }\end{array}$ & [25] \\
\hline & $\begin{array}{c}1077 / 1076 \\
\text { (medium broad band) }\end{array}$ & $\begin{array}{l}\text { Antisymmetric stretching of C-O group } \\
\text { of polysaccharides and/or chlorophyll }\end{array}$ & [12] \\
\hline \multirow{3}{*}{ PCT } & $\begin{array}{c}3604,3598 \\
\text { (small peak) }\end{array}$ & Nonbonded hydroxyl groups & [33] \\
\hline & $\begin{array}{l}3500-2500 \\
\text { (very broad band) }\end{array}$ & $\begin{array}{l}\text { Very broad band overlapping the } \\
\text { hydrogen-bonded O-H (the bending } \\
\text { and stretching vibrations of hydroxyl } \\
\text { groups in polysaccharide) and C-H } \\
\text { stretching vibration in the frequency } \\
2830-2695 \mathrm{~cm}^{-1} \text { shown as } \\
\text { carbohydrate ring }\end{array}$ & [25], [33], [34] \\
\hline & 1715 & $\begin{array}{l}\text { Band attributed both to the carboxylic } \\
\text { acid and to the ester groups }\end{array}$ & [33] \\
\hline
\end{tabular}


Table 2. Cont.

\begin{tabular}{|c|c|c|c|}
\hline $\begin{array}{l}\text { Sample } \\
\text { Code }\end{array}$ & FT-IR Bands ( $\left.\mathrm{cm}^{-1}\right)$ & Assignment & Ref. \\
\hline & 1631,1578 & Carboxylate groups (-COO-) & [33] \\
\hline & 1371 (weak) & $\mathrm{O}-\mathrm{H}$ in plane deformation & [13] \\
\hline & $\begin{array}{c}1221 / 1240 \\
\text { (very weak, broad) }\end{array}$ & $\begin{array}{l}\text { Vibrations of the }-\mathrm{C}-\mathrm{O}-\mathrm{C}-\text { and }-\mathrm{C}-\mathrm{O}-\mathrm{H} \\
\text { bonds present in polysaccharide } \\
\text { structures }\end{array}$ & [33], [35] \\
\hline & 1050 (sharp band) & $-\mathrm{C}-\mathrm{O}-\mathrm{C}-$ ether linkage of pectin & [1], [36] \\
\hline & 830 (weak, sharp peak) & $\begin{array}{l}\text { Hydrogen-bonded O-H out-of-plane } \\
\text { bending }\end{array}$ & [33] \\
\hline \multirow{4}{*}{ MNT-nAg/AMT-nAg } & $\begin{array}{l}\text { 3345/3363 (intense, very } \\
\text { broad band) }\end{array}$ & $\begin{array}{l}\text { This band indicates the presence of } \\
\text { hydroxyl groups on the surface of } \\
\text { nanoparticles. }\end{array}$ & [3] \\
\hline & $\begin{array}{c}\text { 2933/2935 } \\
\text { (weak, sharp band) }\end{array}$ & Alkyls C-H stretching vibration & [33] \\
\hline & 1620/1622 (strong sharp band) & $\begin{array}{l}\text { Amide I, arising due to carbonyl }(-\mathrm{C}=\mathrm{O}) \\
\text { stretch in proteins }\end{array}$ & [25] \\
\hline & 1073/1075 (weak band) & $\begin{array}{l}\text { Stretching vibration to }-\mathrm{C}-\mathrm{O}-\mathrm{C}-\text { groups } \\
\text { of polysaccharides }\end{array}$ & [12] \\
\hline \multirow{5}{*}{ MNT-nAg-PCT/AMT-nAg-PCT } & $\begin{array}{l}3519-2905 / 3571-2515 \\
\text { (strong broad band) }\end{array}$ & $\begin{array}{l}\text { Stretching vibration of } \mathrm{O}-\mathrm{H} \text { groups that } \\
\text { interact by } \mathrm{H} \text { bonding }(\mathrm{O}-\mathrm{H}-\mathrm{O}) \text {, the } \\
\text { major contributors to this band being } \\
\text { polysaccharides and polyphenolic } \\
\text { compounds) }\end{array}$ & [13] \\
\hline & $1738 / 1747$ & $\begin{array}{c}-\mathrm{C}=\mathrm{O} \text { stretching of esterified carboxylic } \\
\text { groups } \\
\left(-\mathrm{COOCH}_{3}\right)\end{array}$ & [37] \\
\hline & $\begin{array}{c}1634 / 1582 \\
\text { (this band weakened) }\end{array}$ & Carboxylate groups (-COO-) & [33] \\
\hline & $1448 / 1448$ & $\begin{array}{l}\mathrm{C}-\mathrm{H} \text { asymmetric bend of methyl group } \\
\text { of pectin }\end{array}$ & [33] \\
\hline & $1109 / 1105$ & $\begin{array}{l}v(\mathrm{CO}), v(\mathrm{CC}) \text { ring of polysaccharides, } \\
\text { and pectin }\end{array}$ & [1] \\
\hline
\end{tabular}

\subsection{Structural Investigation of the Samples}

All the samples were investigated from structural point of view. Thus, X-ray diffraction patterns of developed "green" silver nanoparticles MNT-nAg and AMT-nAg (Figure 4) exhibited diffraction peaks at $38.1^{\circ}, 44.3^{\circ}$, and $64.4^{\circ}$ corresponding to the Miller indices of the reflecting planes (111), (200) and (220) indexed to silver in cubic phase, space group: Fm-3m (225) (ICDD file no. 004-0783).

The biohybrids based on AgNPs coated with pectin (MNT-nAg-PCT and AMT-nAg-PCT) exhibited also the typical structural signature of silver in cubic phase.

The presence of other peaks in AgNP X-ray diffractograms could be interpreted as the presence of crystallized organic compounds (arising from plant extracts) located on the surface of the nanoparticles [38].

\subsection{Elemental Composition of the Samples}

The elemental composition of the samples was studied by XPS. Figure 5a shows the typical XPS survey spectrum for MNT-nAg-PCT sample, indicating the existence of $\mathrm{Ag}, \mathrm{C}, \mathrm{O}, \mathrm{Ca}, \mathrm{K}$ and N. The C1 peak observed at a binding energy (BE) of $\sim 284.8 \mathrm{eV}$ corresponding to $\mathrm{C}-\mathrm{C}$ and $\mathrm{C}-\mathrm{H}$ bonds serves as a reference to correct the binding energy shift. The $\mathrm{C} 1$ spectrum (Figure $5 \mathrm{~b}$ ) was deconvoluted in more peaks corresponding to carbon-nitrogen bonds ( $284.81 \mathrm{eV})$, carboxyl group (286.51 eV), carbonyl group $(287.92 \mathrm{eV})$, carboxylate group $(288.99 \mathrm{eV})$. The peak of the $\mathrm{O} 1$ was also deconvoluted into four bands, as it is presented in Figure $5 \mathrm{c}$. The peak at $531.45 \mathrm{eV}$ corresponds to a carbonyl group, and a carboxyl group linked to aliphatic chain is denoted at $532.56 \mathrm{eV}$, along with a carboxyl group linked to aromatic ring at $533.46 \mathrm{eV}$. Additionally, water traces were evidenced at $534.39 \mathrm{eV}$. The high-resolution 
XPS spectrum of Ag3d is shown in Figure $5 \mathrm{~d}$ and was deconvoluted into two peaks corresponding to $\mathrm{Ag} 3 \mathrm{~d}^{3 / 2}(374.29 \mathrm{eV})$ and $\mathrm{Ag} 3 \mathrm{~d}^{5 / 2}(368.23 \mathrm{eV})$ spectral lines, which are attributed to metallic $\mathrm{Ag}$ [39].

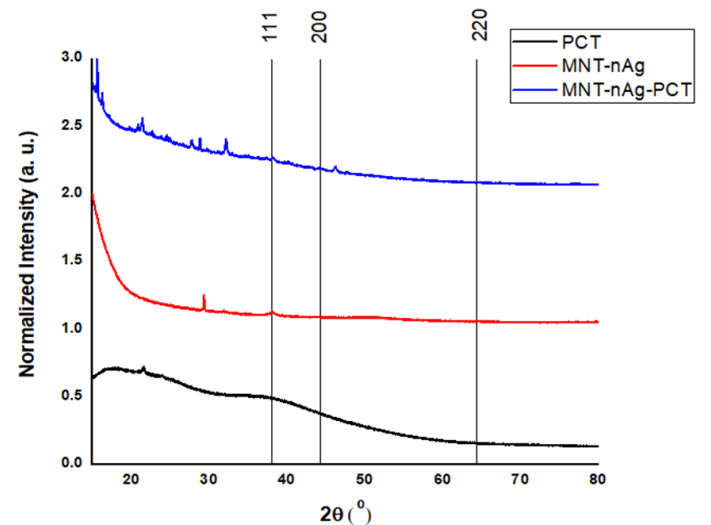

(a)

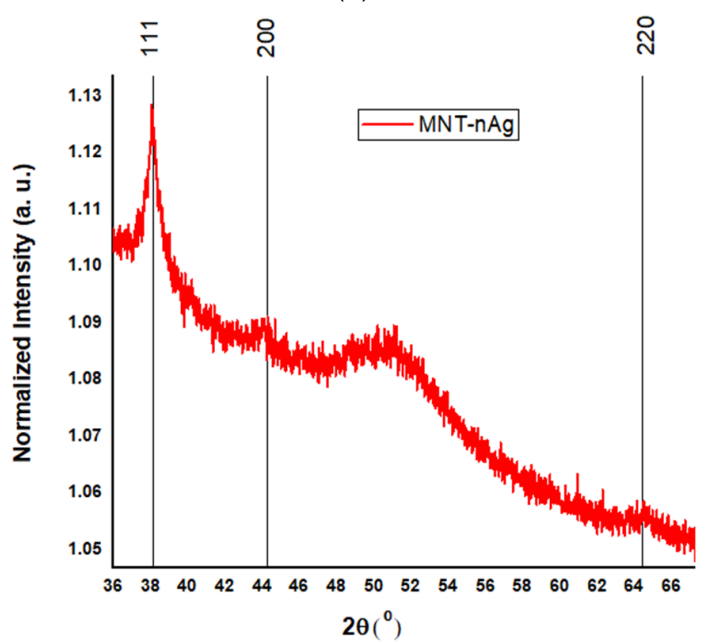

(c)

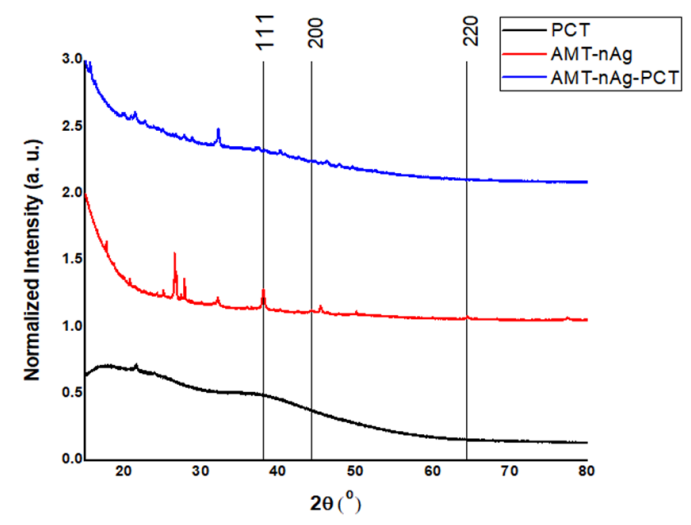

(b)

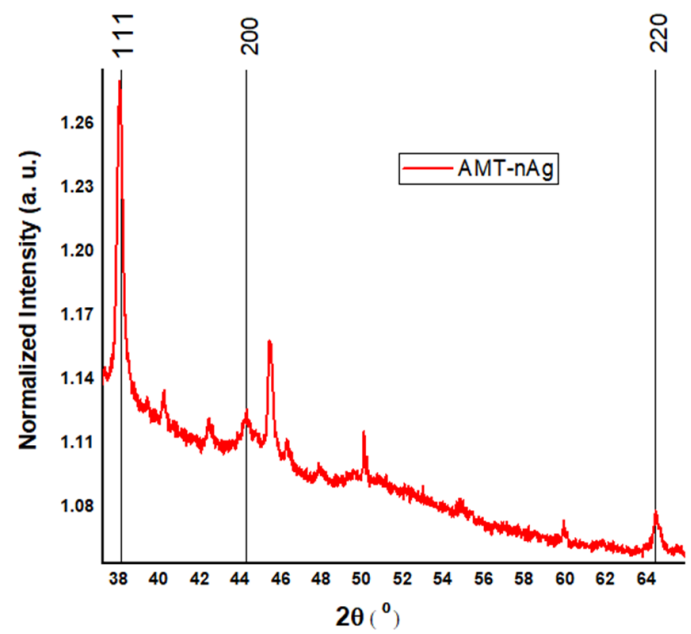

(d)

Figure 4. X-ray Diffraction XRD patterns of investigated samples. Comparative representation of diffraction peaks of the samples derived from Mentha piperita (a) and Amaranthus retroflexus (b). Typical structural signature of silver in cubic phase for silver nanoparticles generated from Mentha piperita (c) and Amaranthus retroflexus (d).

From the XPS survey spectrum, the atomic percentages of $\mathrm{Ag}, \mathrm{C}, \mathrm{O}, \mathrm{Ca}, \mathrm{K}$ and $\mathrm{N}$ elements were also found to be $0.1 \%, 60.6 \%, 35.7 \%, 0.2 \%, 0.4 \%$ and $3 \%$, respectively.

It can be concluded that the investigated sample contains only metallic silver nanoparticles embedded in pectin matrix, with similar XPS data also recorded for the other samples.

\subsection{Evaluation of Zeta Potential of the Pectin-Coated Materials}

The interaction between biogenic AgNPs and pectin was followed also by Zeta potential $(\xi)$ measurements. Zeta potential is a key factor in establishing the physical stability and it is close related to the electrical particle charge. 

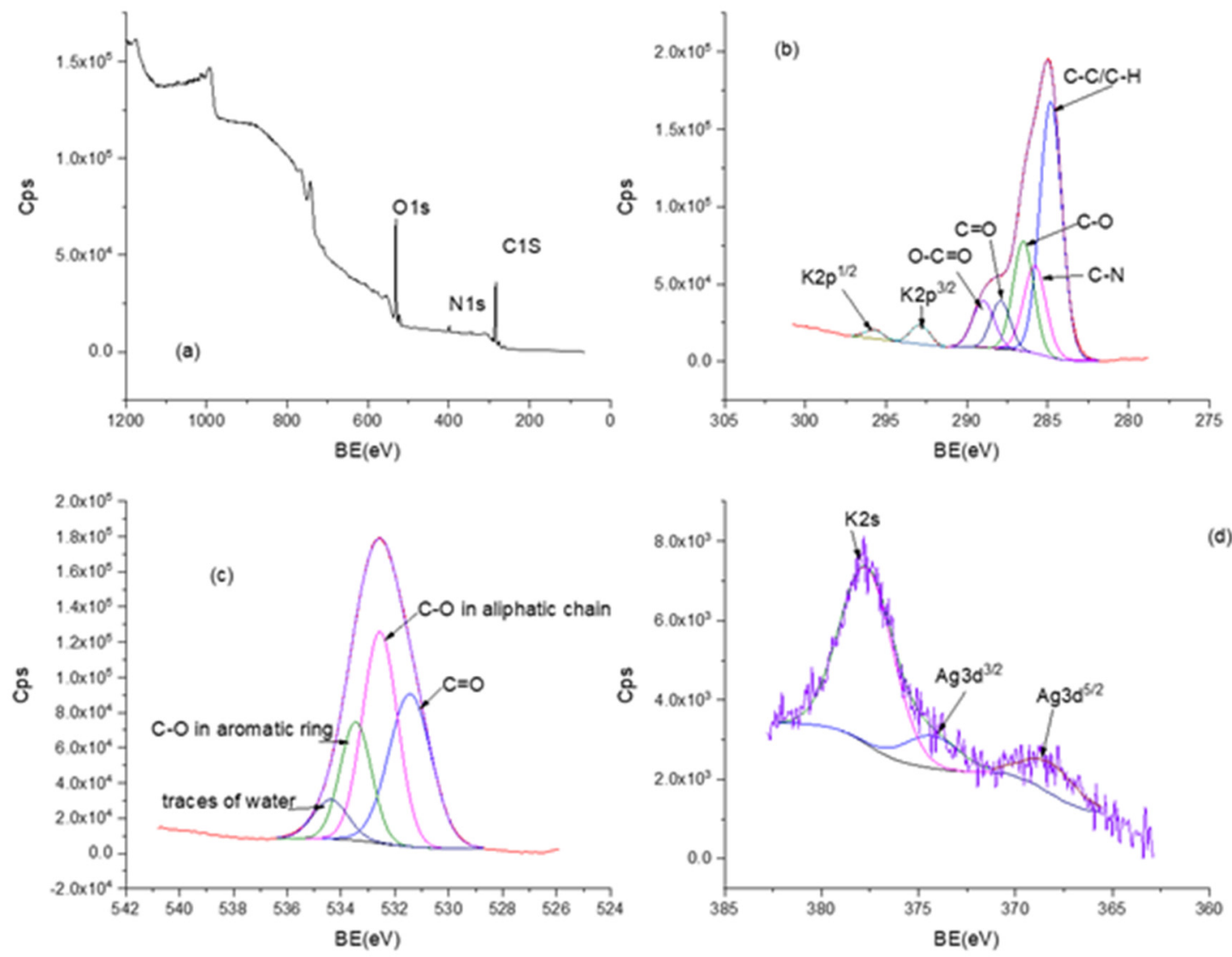

Figure 5. X-ray Photoelectron Spectroscopy (XPS) spectra of MNT-nAg-PCT sample: survey spectrum (a); C1 spectrum (b); O1 spectrum (c); Ag3d spectrum (d).

Figure 6 shows the Zeta potential values of the silver-based materials developed in this research. MNT-nAg exhibited moderate stability $(\xi=-17 \mathrm{mV})$, while AMT-nAg showed good physical stability $(\xi=-32.3 \mathrm{mV})$ provided by electrostatic repulsion between nanoparticles. After pectin addition, the $\xi$ values reached the value of $-10.7 \mathrm{mV}$ for MNT-nAg-PCT, and $-17.81 \mathrm{mV}$ for AMT-nAg-PCT.

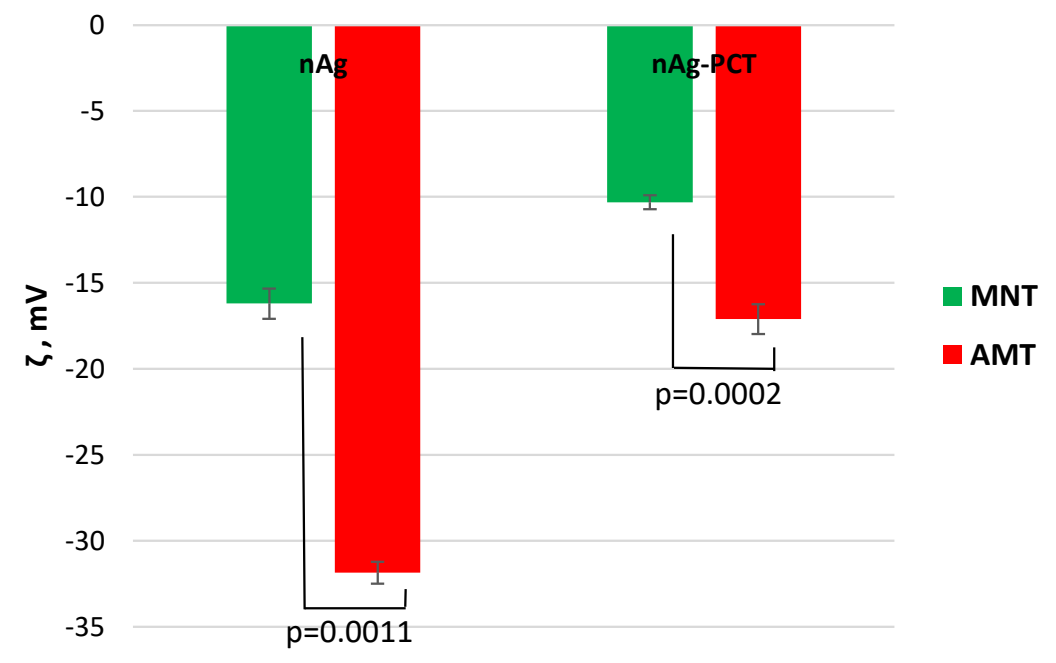

Figure 6. Zeta potential values of the silver-based materials.

The $p$-values $(p \leq 0.05)$ from the $t$-test are indicated in Figure 6 . 


\subsection{Size and Morphological Studies of Pectin-Coated Materials}

Size determination of the phytogenic nanoparticles, estimated by DLS measurements, is displayed in Figure 7, correlated with the $p$-values from the $t$-test $(p \leq 0.05)$.

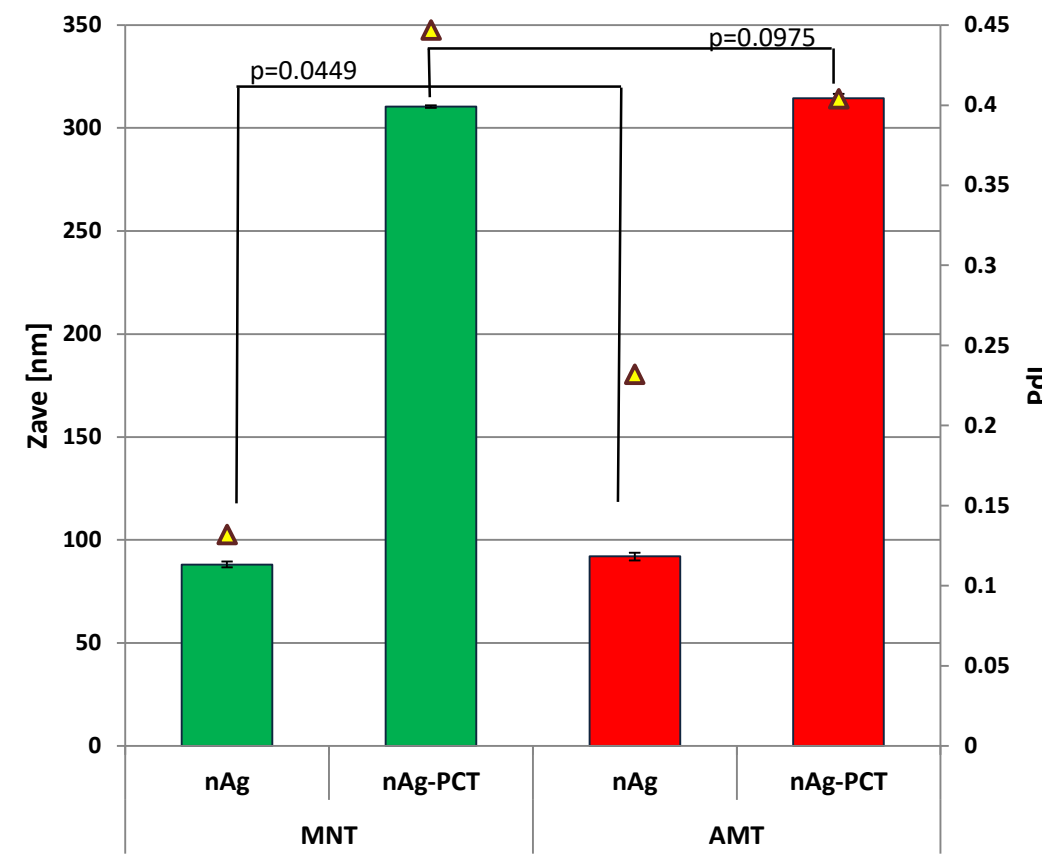

$\Delta \mathrm{Pdl}$

Figure 7. The average size $\left(\mathrm{Z}_{\mathrm{ave}}, \mathrm{nm}\right)$ and polydispersity index (PdI) of phytogenic nanoparticles, estimated by Dynamic Light Scattering (DLS) measurements.

DLS results yielded a monomodal distribution with a hydrodynamic diameter around $88 \pm 3.56 \mathrm{~nm}$ for MNT-nAg and $92 \pm 7.1 \mathrm{~nm}$ for AMT-nAg, while pectin-silver composites presented larger diameters: $310.5 \pm 9.4 \mathrm{~nm}($ MNT-nAg-PCT) and $314.4 \pm 10.8 \mathrm{~nm}$ (AMT-nAg-PCT).

The DLS measurements indicate that the particle size distribution for phytogenic AgNPs was nearly monodisperse (with PdI values of 0.132 for MNT-nAg, and 0.232 for AMT-nAg), while pectin-coated AgNPs presented slightly broad particle size distribution (with PdI values of 0.447 for MNT-nAg-PCT, and 0.404 for AMT-nAg-PCT). These findings agree with UV-Vis absorption results and were further confirmed by microscopic analysis.

Morphological aspects-the size and shape of the nanoparticles developed in this study were further investigated by AFM and SEM analysis.

AFM images from Figure 8 showed that the size of MNT-nAg and AMT-nAg are in the nanometer range, and the shape of these nanoparticles is spherical. Based on the histogram distribution of the AgNPs, we calculated the average particle height and found it to be $49.58 \pm 3.7 \mathrm{~nm}$ for MNT-nAg, and $18 \pm 5.3 \mathrm{~nm}$ for AMT-nAg. MNT-nAg showed a more homogenous distribution with less dispersion of the size, findings that agree with DLS results.

Figure 9 displays the AFM images recorded for pectin-coated AgNPs. However, when dried, pectin left a thick layer on top of the AgNPs. As observed from Figure 9, one can distinguish the AgNPs wrapped in a pectin coat.

SEM images (Figure 10) confirmed the phytosynthesis of silver nanoparticles and their biohybrids with pectin and highlighted the nano-scaled size and their spherical shape. As seen, the mean sizes of AMT-nAg are smaller than those of MNT-nAg. Moreover, AMT-nAg is more uniformly distributed than MNT-nAg, as shown also from DLS and zeta potential measurements. Most nanoparticles of MNT-nAg have a mean diameter of $35.7 \mathrm{~nm}$ and presented few aggregates. AMT-nAg presented many nanoparticles with diameters less than $30 \mathrm{~nm}$. 


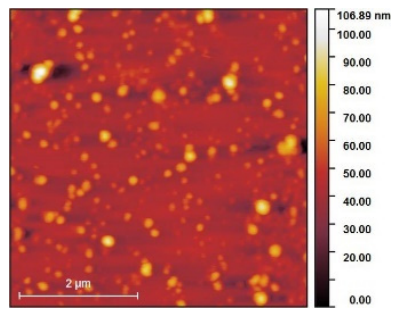

(a)

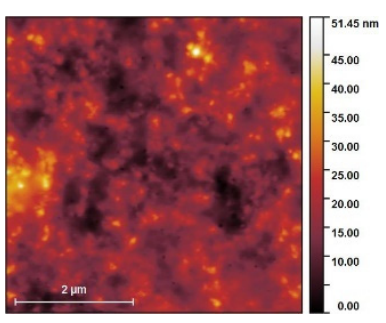

(d)

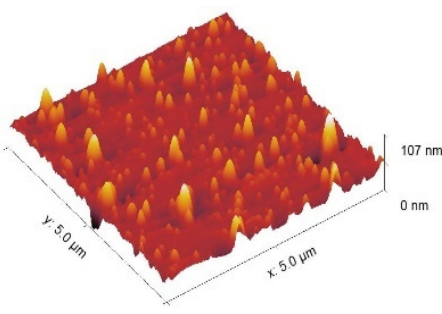

(b)

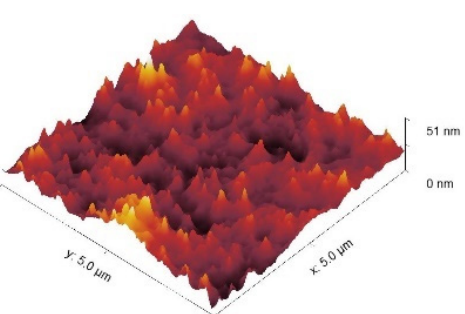

(e)

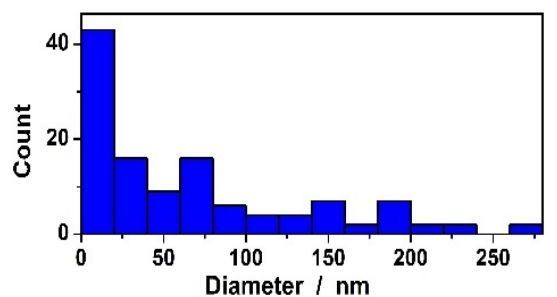

(c)

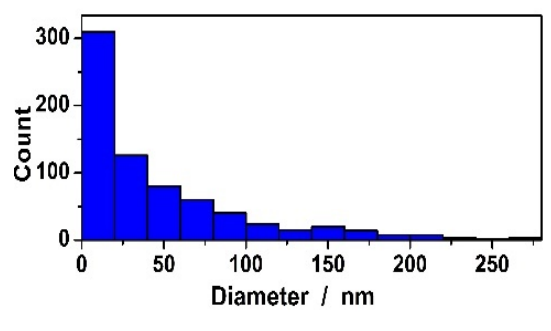

(f)

Figure 8. Morphological characterization of uncoated AgNPs. MNT-nAg (a,b,c), and AMT-nAg (d,e,f): topography $(\mathbf{a}, \mathbf{d})$; three-dimensional $(\mathbf{b}, \mathbf{e})$ and histogram distribution of nanoparticles heights $(\mathbf{c}, \mathbf{f})$ Atomic Force Microscopy (AFM) images.

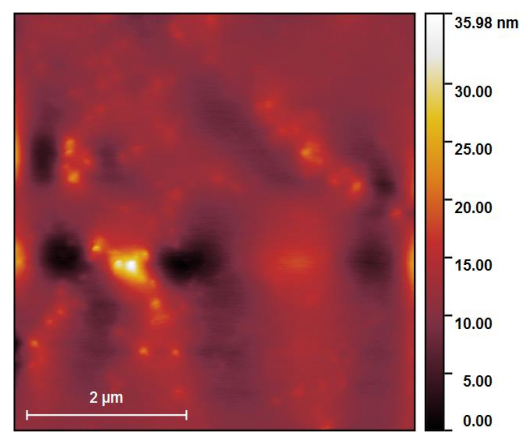

(a)

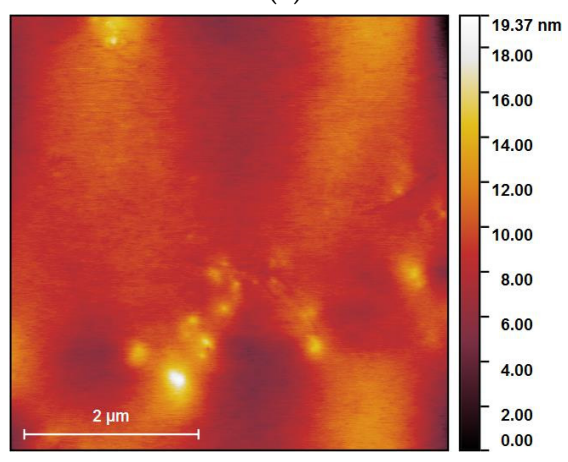

(c)

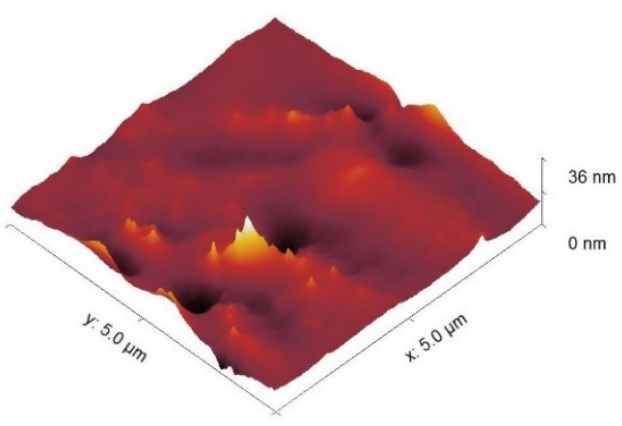

(b)

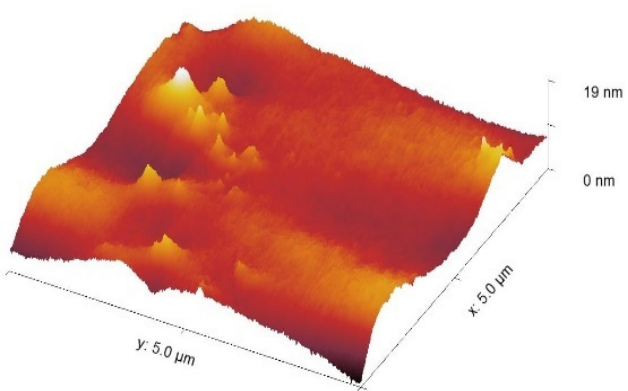

(d)

Figure 9. Morphological characterization of pectin-coated nanoparticles: MNT-nAg-PCT (a,b) and AMT-nAg-PCT (c,d): topography (a,c); and three-dimensional (b,d) AFM images. 

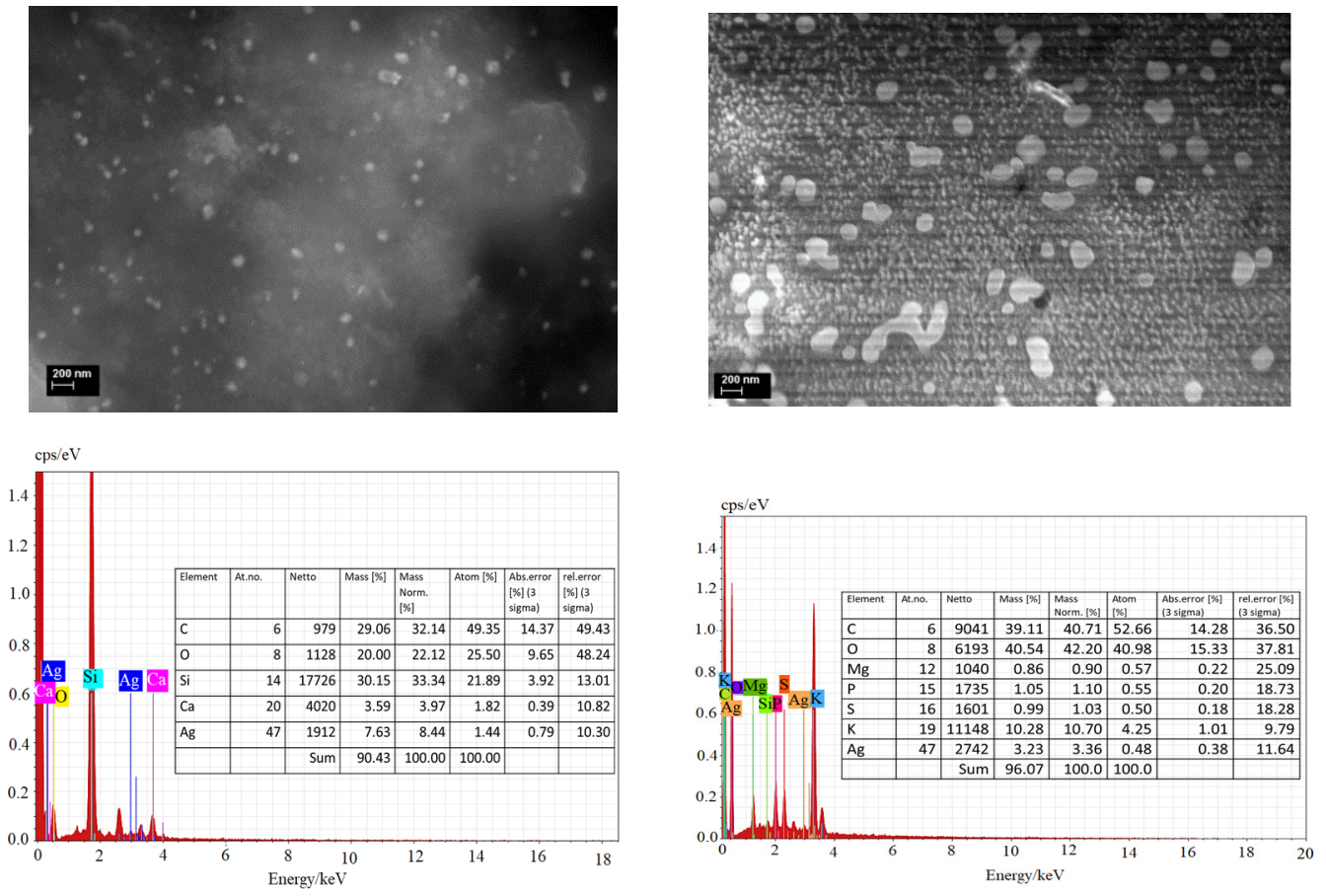

(a)

(b)
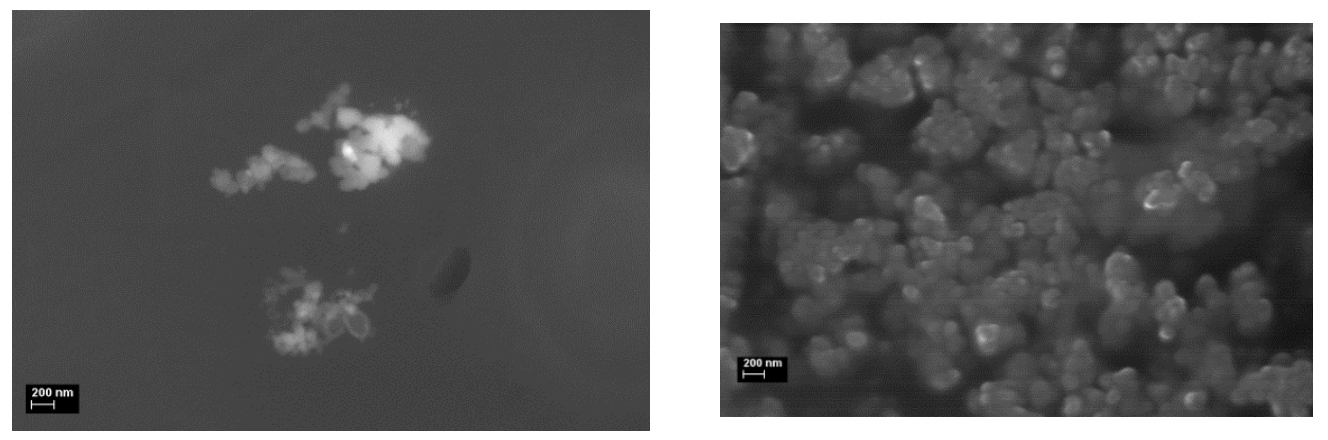

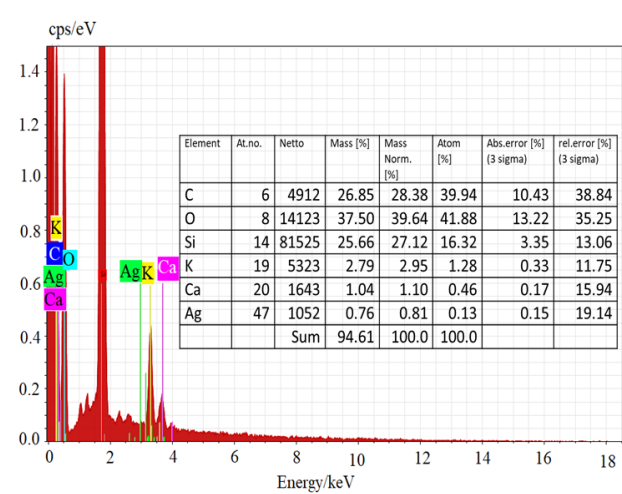

(c)

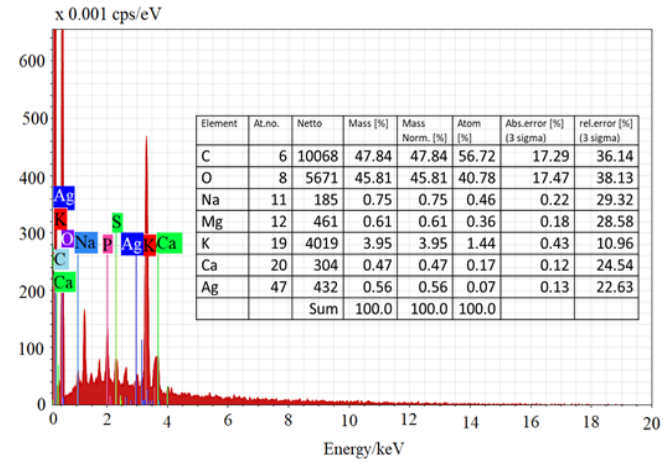

(d)

Figure 10. Scanning Electron Microscopy (SEM) images and EDX spectra of developed uncoated: MNT-nAg (a) and AMT-nAg (b); and pectin-coated: MNT-nAg-PCT (c) and AMT-nAg-PCT (d) silver nanoparticles.

The addition of pectin to these biogenic AgNPs resulted in formation of bigger entities. Thus, MNT-nAg-PCT showed a predominant size of $307 \mathrm{~nm}$, and AMT-nAg-PCT presented a mean size of $260 \mathrm{~nm}$. 
The presence of Ag in all analyzed samples was confirmed by Energy-dispersive X-ray Spectroscopy (EDX) spectra (see Figure 10).

\subsection{Evaluation of Bioactivities of Developed Materials}

The antioxidant behavior of the samples was evaluated through chemiluminescence (CL) method for short-life free radicals (Figure 11a), and through an ABTS assay for long-life free radicals (Figure 11b).

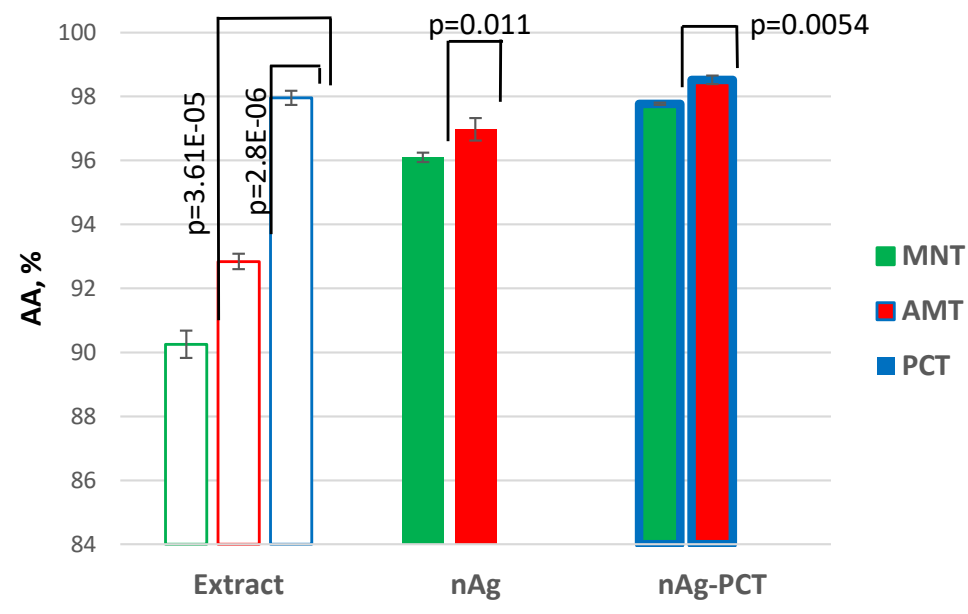

(a)

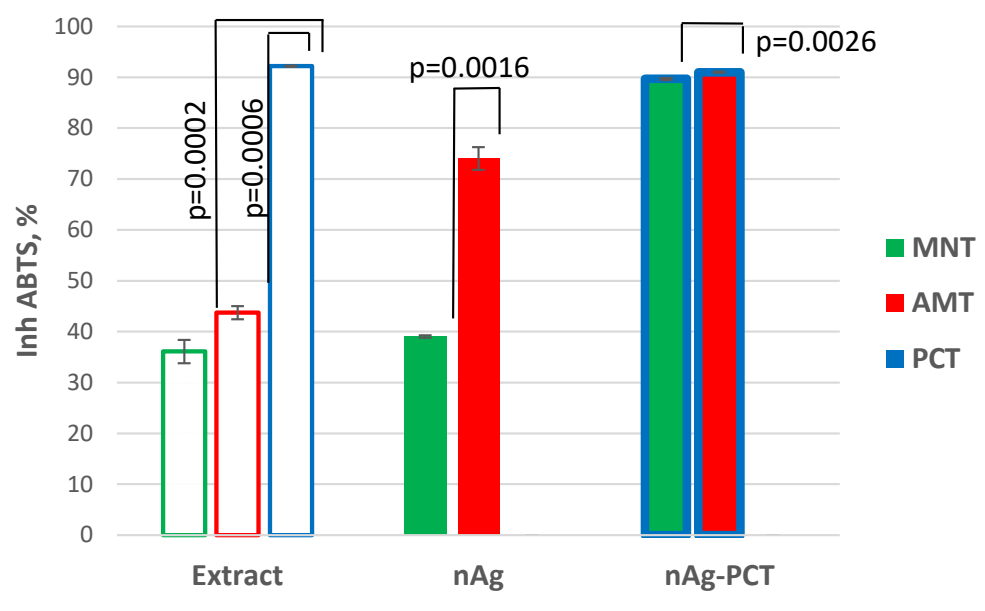

(b)

Figure 11. The antioxidant activity (AA\%) of the samples evaluated by chemiluminescence technique (a) and inhibition of radical ABTS•+ (b).

The antioxidant CL profile of the samples (Figure 11a) revealed the strong ability of all samples to scavenge short-life free radicals. The silver nanoparticles bio generated from exhibited higher AA\% values than those of plant extracts from which AgNPs come. Thus, MNT-nAg and AMT-nAg presented AA \% values of $96.10 \%$ and $97.25 \%$, respectively, values higher than those of their precursors: $\mathrm{AA}_{(\mathrm{MNT})}=90.25 \%$ and $\mathrm{AA}_{\mathrm{AMT}}=92.84 \%$. This behavior of phytogenic AgNPs as compared to their precursor vegetal extracts was demonstrated in our previous studies $[5,17,40]$.

Pectin exhibited high antioxidant activity (97.77\%). The coating of phytosynthesized AgNPs with this biopolymer resulted in biohybrids with enhanced antioxidant capacity $\left(\mathrm{AA}_{(\mathrm{MNT}-\mathrm{nAg}-\mathrm{PCT})}=97.95 \%\right.$ and $\mathrm{AA}_{(\mathrm{AMT}-\mathrm{nAg}-\mathrm{PCT})}=98.70 \%$ ). 
The ABTS assay highlighted that all samples possess the ability for long-life free radicals scavenging (Figure $11 \mathrm{~b}$ ). Thus, the inhibition of ABTS $\bullet^{+}$was $36.12 \%$ for MNT, and $43.73 \%$ for AMT. The biogenic AgNPs generated from these natural extracts exhibited higher ABTS ${ }^{+}$capturing values: $39.1 \%$ for MNT-nAg and $74.02 \%$ for AMT-nAg. The addition of pectin resulted in the development of most potent biohybrids: Inh ABTS $\bullet^{+}{ }_{(\text {MNT-nAg-PCT })}=89.7 \%$ and Inh ABTS $\bullet^{+}{ }_{(\text {AMT-nAg-PCT })}=91 \%$. The $p$-values $(p \leq 0.05)$ from the $t$-test are indicated in Figure 11.

Microbiological testing was carried out on Escherichia coli bacterium, as it is the most common clinical pathogen causing intestinal infection (such as diarrhea, abdominal pain, and fever), and can lead to more severe situations (bloody diarrhea, dehydration, even kidney failure) [41].

Antimicrobial susceptibility was determined on three different days, and MBC values for each isolate were reported as the median of three experiments.

The results obtained for the antimicrobial susceptibility test of AgNPs on the organism showed MBCs of $100 \mu \mathrm{g} / \mathrm{mL}$ (for MNT-nAg-PCT) and $50 \mu \mathrm{g} / \mathrm{mL}$ (for AMT-nAg-PCT) against Escherichia coli. The results are displayed in Table 3.

Table 3. Antimicrobial susceptibility of the microorganisms to AgNPs.

\begin{tabular}{|c|c|c|c|c|c|c|c|c|c|c|c|c|}
\hline \multirow{2}{*}{$\begin{array}{l}\text { Concentration of } \\
\operatorname{AgNPs},(\mu \mathrm{g} / \mathrm{mL}) \text {. }\end{array}$} & \multicolumn{12}{|c|}{ Escherichia Coli } \\
\hline & 400 & 200 & 100 & 50 & 25 & 12.5 & 6.25 & 3.125 & 1.56 & 0.78 & 0.39 & 0.195 \\
\hline MNT-nAg-PCT & $S$ & $S$ & $\mathrm{~S}$ & $\mathrm{R}$ & $\mathrm{R}$ & $\mathrm{R}$ & $\mathrm{R}$ & $\mathrm{R}$ & $\mathrm{R}$ & $\mathrm{R}$ & $\mathrm{R}$ & $\mathrm{R}$ \\
\hline AMT-nAg-PCT & S & S & S & S & $\mathrm{R}$ & $\mathrm{R}$ & $\mathrm{R}$ & $\mathrm{R}$ & $\mathrm{R}$ & $\mathrm{R}$ & $\mathrm{R}$ & $\mathrm{R}$ \\
\hline
\end{tabular}

Key: R-Resistant; S-Susceptible/Sensitivity.

The antibacterial activity of the phytogenic nanoparticles was evaluated by a spread plate method (qualitative method).

The CFUs of the bacteria in each group were counted and bactericidal ratios were calculated according to Equation (3). Three samples per group were tested and the test was repeated three times. The data were presented as mean \pm S.D. (standard deviation) as shown in Table 4 .

Table 4. Colony-forming units of the bacteria in each group, bactericidal ratios, and susceptibility constant for each developed nanoparticle.

\begin{tabular}{cccc}
\hline Specimen & CFUs, Escherichia Coli & Bactericidal Ratio (R)\% & $\begin{array}{c}\text { Susceptibility Constant } \\
\text { (Z Value) } \\
\text { mL/ } \boldsymbol{\mu g}\end{array}$ \\
\hline MNT & $671 \pm 4.5$ & NBR & NBR \\
MNT-nAg & $93 \pm 7.5$ & 86 & 0.01976 \\
MNT-nAg-PCT & $82 \pm 1.52$ & 87.7 & 0.02102 \\
AMT & $648 \pm 4.5$ & NBR & NBR \\
AMT-nAg & $84 \pm 2.5$ & 87 & 0.0408 \\
AMT-nAg-PCT & $77 \pm 1.5$ & 88 & 0.0426 \\
\hline
\end{tabular}

NBR-No bactericidal ratio.

In the samples without AgNPs, a more pronounced growth of Escherichia coli was observed ( $>600 \mathrm{UFC} / \mathrm{mL}$ versus $<95 \mathrm{CFU} / \mathrm{mL}$ for treated sample).

The bactericidal activity results show that this nanocomposite is strongly active against the Escherichia coli, so it can be considered as an antibacterial coating.

At a concentration of $100 \mu \mathrm{g} / \mathrm{mL}$ and $50 \mu \mathrm{g} / \mathrm{mL}$ of MNT-nAg and AMT-nAg, respectively, the silver nanoparticle susceptibility constant ( $\mathrm{Z}$ value) was determined by Equation (4).

The reaction of silver nanoparticles with an average size of $18 \mathrm{~nm}$ with Escherichia coli showed the highest susceptibility $(\mathrm{Z}=0.0426 \mathrm{~mL} / \mu \mathrm{g})$ for the AMT-nAg-PCT sample.

Table 5 displays the photographs of Petri dishes inoculated with the samples during the agar well diffusion assay. The values of inhibition zone are impressive for pectin-based biohybrids: $I Z=39 \pm 0.62$ for AMT-nAg-PCT and IZ $=35 \pm 0.58$ for MNT-nAg-PCT, as compared to their components alone: $\mathrm{IZ}_{\mathrm{MNT}-\mathrm{nAg}}=21 \pm 0.46 \mathrm{~mm} ; \mathrm{IZ}_{\mathrm{AMT}-\mathrm{nAg}}=25 \pm 0.26 \mathrm{~mm} ; \mathrm{IZ}_{\mathrm{PCT}}=12 \pm 0.32 \mathrm{~mm}$. Of all the samples, pectin alone showed the poorest antibacterial effect. 
Table 5. Antibacterial activity (against Escherichia coli) of the prepared samples, estimated by agar well diffusion method.

\begin{tabular}{lcc}
\hline Sample & $\begin{array}{c}\text { Photographs of Petri Dishes } \\
\text { Inoculated with Samples }\end{array}$ & $\begin{array}{c}\text { Inhibition Zone, } \\
\text { IZ (mm) }\end{array}$ \\
\hline PCT & $12 \pm 0.32$ \\
\hline
\end{tabular}
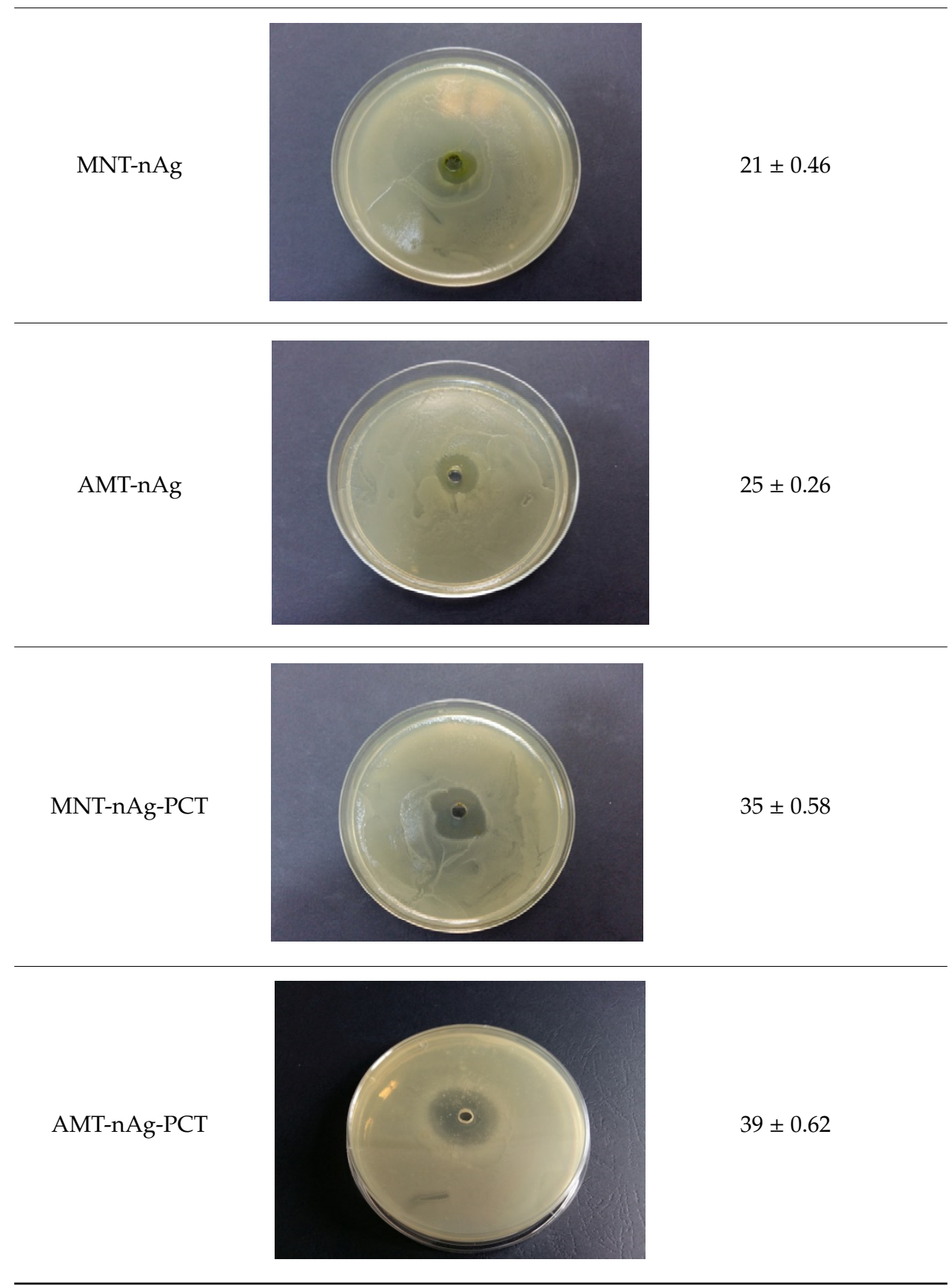


\section{Discussion}

To the best of our knowledge, this is the first report about the bottom-up eco-design of biohybrids achieved by pectin coating the biogenic AgNPs generated from Mentha piperita and Amaranthus retroflexus, and their characterization by combining modern biophysical techniques.

The UV-Vis absorption spectra showed that phytocompounds present in the vegetal extracts (such as polysaccharides, amino acids, proteins, polyphenols, flavonoids, as mentioned in Section 3.1) may reduce $\mathrm{Ag}^{+}$into $\mathrm{Ag}^{0}$. The bio-constituents of plant extracts acted both as reducing and capping agents, resulting in phytogenic silver nanoparticles. The phyto-assisted synthesis of AgNPs was confirmed by the apparition of a single SPR band located at $435 \mathrm{~nm}$ (MNT-nAg) and at $397 \mathrm{~nm}$ (AMT-nAg) (Figure 2b), respectively, which is typical for spherical silver nanoparticles [42]. Given the location of the SPR band, we can assume that the mean size of the AMT-nAg will be greater than that of the MNT-nAg, because maximum absorption peaks at longer wavelengths suggest bigger diameters of nanoparticles, while particles with smaller sizes interact with light at shorter wavelengths [43].

After the addition of pectin to the bio-AgNPs, some spectral changes occurred (Figure 2a). Thus, in the absorption spectrum of MNT-nAg-PCT, the trough at 255 shifted to $252 \mathrm{~nm}$, and the trough at $327 \mathrm{~nm}$ disappeared. Furthermore, in the absorption spectrum of AMT-nAg-PCT, the trough at 299 shifted to $307 \mathrm{~nm}$, and the peak at $320 \mathrm{~nm}$ became a shoulder (like the PCT spectrum). These findings showed that the key molecules in silver nanoparticles formation and stabilization are proteins, polyphenols and polysaccharides arising from plant extracts.

The spectral changes in FT-IR spectra (shifts of FT-IR bands belonging to polyphenols, proteins, and also the slight shift and the diminishing of peaks corresponding to $-\mathrm{C}-\mathrm{O}-\mathrm{C}-$ groups of polysaccharides) demonstrated the phytosynthesis of MNT-nAg and AMT-nAg. The broadening of FT-IR bands attributed to the bending and stretching vibrations of $\mathrm{O}-\mathrm{H}$ groups revealed that MNT-nAg and AMT-nAg wear hydroxyl groups on their surface. The addition of pectin to AgNPs resulted in the intensifying and broadening of the peaks at 3345 (MNT-nAg) and $3363 \mathrm{~cm}^{-1}$ (AMT-nAg), attributed to the bending and stretching vibrations of hydroxyl groups. Moreover, the bands attributed to carboxylate groups (-COO-) weakened and shifted, while the bands assigned to the ester groups increased in intensity and shifted. These findings showed that more carboxylate and hydroxyl groups of pectin are involved in realization of hydrogen bonds with functional groups belonging to capping agents on surface of "green" synthesized AgNPs.

The XPS analysis confirmed the presence of some chemical groups on the surface of the nanoparticles, especially $\mathrm{O}-\mathrm{H},-\mathrm{C}-\mathrm{O},-\mathrm{C}=\mathrm{O},-\mathrm{COOH}$ groups, the results of which are in agreement with the FT-IR investigation.

X-ray diffractograms showed the signature of silver in cubic phase both in AgNPs and in their pectin-based biohybrids. The XRD pattern of pectin indicated a broad diffraction peak at around the 13-35 degree, confirming the completely amorphous character of this biopolymer as indicated also by Vedhanayagama et al. [36]. Moreover, the appearance of other peaks in the X-ray diffractograms of pectin-coated silver nanoparticles, at around the 13-35 degree, indicated that the crystallinity of pectin increases after the incorporation of AgNPs due to the formation of hydrogen bonds between pectin and phytogenic AgNPs [36], findings that are in agreement with FTIR and XPS results.

The biogenic AgNPs possess negative surface charge, estimated by zeta potential measurements, and tend to repel each other due to the presence of negatively-charged functional groups (like carboxylate) arising from capping agents bearing on the AgNP surface, as proved by FT-IR analysis. After pectin addition to the phytosynthesized AgNPs, the $\xi$ values changed to $-10.7 \mathrm{mV}$ for MNT-nAg-PCT, and to $-17.81 \mathrm{mV}$ for AMT-nAg-PCT, because large molecules, like pectin, tend to adsorb at nanoparticle surface through the carboxyl and hydroxyl groups, decreasing the Zeta potential, without affecting the stabilization properties [44]. These non-covalent interactions (hydrogen bonding, hydrophobic, and van der Waals forces) were highlighted also by FT-IR spectra. These findings, together with those obtained by spectral (UV-Vis, FT-IR, DLS), and microscopic (AFM, SEM) investigations suggest that the developed pectin-based hybrids are stabilized sterically. 
The DLS results coupled with AFM and SEM images demonstrate the nano-scale size of phytogenerated particles. The difference between particle size data obtained by DLS and microscopy (AFM and SEM) is that the microscopic techniques require a thin layer deposition of the sample on a plane substrate, and only a limited number of particles can be assessed, while the DLS method measures all particles in the sample analyzed $[38,45]$. Moreover, DLS provides a mean hydrodynamic diameter (the particle diameter plus the double-layer thickness) slightly bigger than physical diameter [45,46].

Taking into account the above-exposed findings in our study, the possible mechanism of the formation of the pectin coat on AgNPs "green" developed from the herbs Mentha piperita and Amaranthus retroflexus is presented in Figure 12.

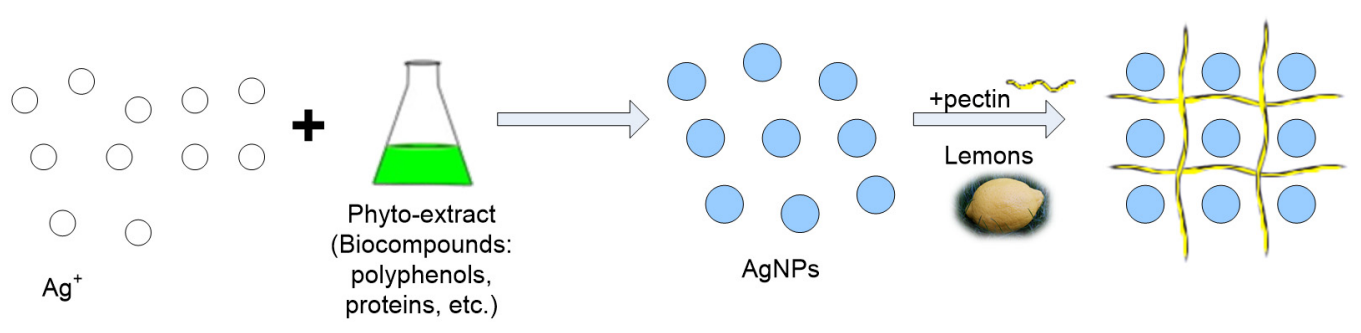

Figure 12. The mechanism of formation of pectin coat on developed AgNPs.

The materials developed in this study exhibited interesting bioactivities.

The amplified antioxidant efficacy of the pectin-coated AgNPs is due to the presence of pectin which is a bioactive biopolymer with antioxidant power [47] attributed to the numerous hydroxyl groups found in its structure [48].

The best antioxidant systems proved to be the biohybrids generated from Amaranthus retroflexus, showing a remarkable ability to scavenge both short-life and long-life free radicals.

The presence of pectin in the biohybrids developed in this work exerted a beneficial effect for antibacterial efficacy against Escherichia coli. The strong antibacterial action of pectin-based biohybrids is due to the composition of these materials which include:

a. pectin coating that facilitates adhesion to bacterial membrane, enhancing the effect of biocidal agents contained in biohybrids, due to delivery-promoting action $[49,50]$.

b. "green" silver nanoparticles which combine the antibacterial effect of nano-silver with that of active phyto-compounds on the AgNP surface [3].

As is known, the lipid membranes are the first target of the attack of biocidal agents. Thus, the presence of pectin assures a tight physical contact between biohybrids and bacteria cell. This interaction may affect the lipopolysaccharides and the membrane proteins of the bacterial cell, altering their membrane permeability [12].

Moreover, the pectin-coated hybrids developed in this study are negatively charged (as demonstrated by Zeta potential measurements) and they could efficiently interact with the membrane via the insertion of their hydrophobic moieties (derived from capping agents on the surface of AgNPs) into the lipid bilayer disturbing them [50,51]. One explanation of the differences between AMT- and MNT-based samples would be the lysine content of the AMT composition [52] which has a great antibacterial effect [53].

Future research directions would be the use of these pectin-coated AgNPs as building blocks to achieve new materials with enhanced bio-performances.

\section{Conclusions}

This work presented the synthesis of pectin-coated bio-nanosilver by using a "green" design. Silver nanoparticles were phyto-generated from two common garden herbs: Mentha piperita and Amaranthus retroflexus. The natural polysaccharide-pectin-was extracted from fresh lemon peels. Phyto-mediated metallic nanoparticle synthesis represents an attractive method due to the use of very accessible biological materials with improved bioactivities. 
The "green" synthesis of AgNPs, and also the bio-formation of pectin-coated AgNPs, were demonstrated by optical (UV-Vis, FT-IR), structural (XRD) and microscopy (AFM, SEM) analyses, and also by DLS and zeta potential measurements. The results obtained from all these methods of investigations are well correlated. AFM and SEM images together with DLS results revealed the nano-dimensions of the obtained materials. UV-Vis and FT-IR analyses showed that the spectral profile of phytogenic AgNPs developed in this research changed after pectin addition. The FT-IR investigation revealed the main phyto-constituents involved in the "green" synthesis of AgNPs, and the interaction (based on hydrogen bonding, or van der Waals interaction) involved in the formation of pectin-coated AgNPs. The chemical composition of materials was investigated by XPS and by EDX. AgNPs were identified through XPS, and it was found that the investigated samples contain only metallic silver nanoparticles embedded in pectin matrix. The presence of Ag in all analyzed samples was evidenced by EDX measurements.

The presence of pectin intensified the bioactivity of "green"-synthesized AgNP, pectin-coated AgNPs appearing to be more bio performant than AgNPs alone. Thus, the pectin-based materials presented a superior ability to scavenge free radicals $(97 \% \div 98.5 \%$ for short-life free radicals, and between $89.7 \% \div 91 \%$ for long-life free radicals) than AgNPs alone $(96.1 \% \div 97.25 \%$ for short-life free radicals, and between $39.1 \% \div 74.02 \%$ for long-life free radicals). Microbiological analyses demonstrated the impressive biocidal properties of the pectin-coated AgNPs, against the common clinical pathogen Escherichia coli.

The nanoparticles derived from Amaranthus retroflexus proved to be the strong antioxidant systems, and the most effective against Escherichia coli.

This research brings new ways for the efficient valorization of common garden herbs, which are natural resources that are found in abundance in nature. The new eco-designed hybrids could be applied as antibacterial and antioxidant coatings for various biomedical applications.

Author Contributions: Conceptualization, M.E.B.-P., C.U., and N.B.; Investigation, M.E.B.-P., C.U., N.B., M.B., A.L.-S., I.Z., C.B., M.E., and C.N.; Methodology, M.E.B.-P., C.U., and N.B.; Writing original draft: M.E.B.-P.; Writing-review and editing, M.E.B.-P., C.U., N.B., M.B., A.L.-S., I.Z., and C.B.; Visualization, M.E.B.-P., C.U., and N.B.; Supervision, M.E.B.-P. All authors have read and agreed to the published version of the manuscript.

Funding: The present study was supported by the Projects JINR-Romania: Project No.48/ 2020 (Theme No.04-4-1121-2015/2020) and Project No. 75/2020 (Theme No. 04-4-1141-2020/2022) (IUCN ORDER no.269/20.05.2020) of JINR—Romania (University of Bucharest) collaboration. A.L.-S. acknowledges the financial support of the Nucleu Programme at I.N.F.L.P.R., LAPLAS IV, contract no. 16N/08.02.2019. M.B. acknowledges the financial support of the Romanian National Authority for Research and Innovation (PN 1809 02 02/2018 and PN 190602 03/2019). I.Z. acknowledges the financial support of the Romanian National Authority for Research and Innovation through Core Program PN19-030101 (contract no. 21N/2019).

Conflicts of Interest: The authors declare no conflict of interest.

\section{References}

1. Barbinta-Patrascu, M.E.; Badea, N.; Ungureanu, C.; Iordache, S.M.; Constantin, M.; Purcar, V.; Pirvu, C.; Rau, I. Eco-biophysical aspects on nanosilver bio-generated from Citrus reticulata peels, as potential bio-pesticide for controlling pathogens and wetland plants in aquatic media. J. Nanomater. 2017, 2017, 4214017. [CrossRef]

2. Fierascu, I.; Fierascu, I.C.; Dinu-Pirvu, C.E.; Fierascu, R.C.; Anuta, V.; Velescu, B.S.; Jinga, M.; Jinga, V. A Short overview of recent developments on antimicrobial coatings based on phytosynthesized metal nanoparticles. Coatings 2019, 9, 787. [CrossRef]

3. Barbinta-Patrascu, M.E.; Badea, N.; Bacalum, M.; Ungureanu, C.; Suica-Bunghez, I.R.; Iordache, S.M.; Pirvu, C.; Zgura, I.; Maraloiu, V.A. 3D hybrid structures based on biomimetic membranes and Caryophyllus aromaticus_-“Green” synthesized nano-silver with improved bioperformances. Mater. Sci. Eng. C 2019, 101, 120-137. [CrossRef] [PubMed]

4. Barbinta-Patrascu, M.E.; Badea, N.; Bacalum, M.; Antohe, S. Novel bio-friendly nanomaterials based on artificial cell membranes, chitosan and silver nanoparticles phytogenerated from Eugenia caryophyllata buds: Eco-synthesis, characterization and evaluation of bioactivities. Rom. Rep. Phys. 2020, 72, 601. [CrossRef] 
5. Barbinta-Patrascu, M.E.; Ungureanu, C.; Iordache, S.M.; Bunghez, I.R.; Badea, N.; Rau, I. Green silver nanobioarchitectures with amplified antioxidant and antimicrobial properties. J. Mater. Chem. B 2014, 2, 3221-3231. [CrossRef]

6. Khan, S.U.; Saleh, T.A.; Wahab, A.; Khan, M.H.U.; Khan, D.; Khan, W.U.; Rahim, A.; Kamal, S.; Khan, F.U.; Fahad, S. Nanosilver: New ageless and versatile biomedical therapeutic scaffold. Int. J. Nanomed. 2018, 13, 733-762. [CrossRef]

7. Valdés, A.; Burgos, N.; Jiménez, A.; Garrigós, M.C. Natural pectin polysaccharides as edible coatings. Coatings 2015, 5, 865-886. [CrossRef]

8. Muñoz-Bonilla, A.; Echeverria, C.; Sonseca, A.; Arrieta, M.P.; Fernández-García, M. Bio-based polymers with antimicrobial properties towards sustainable development. Materials 2019, 12, 641. [CrossRef]

9. Treviño-Garza, M.Z.; Correa-Cerón, R.C.; Ortiz-Lechuga, E.G.; Solís-Arévalo, K.K.; Castillo-Hernández, S.L.; Gallardo-Rivera, C.T.; Niño, K.A. Effect of linseed (linum usitatissimum) mucilage and chitosan edible coatings on quality and shelf-life of fresh-cut cantaloupe (cucumis melo). Coatings 2019, 9, 368. [CrossRef]

10. Maftoonazad, N.; Ramaswamy, H.S. Application and evaluation of a pectin-based edible coating process for quality change kinetics and shelf-life extension of lime fruit (citrus aurantifolium). Coatings 2019, 9, 285. [CrossRef]

11. Zahran, M.K.; Ahmed, H.B.; El-Rafie, M.H. Facile size-regulated synthesis of silver nanoparticles using pectin. Carbohydr. Polym. 2014, 111, 971-978. [CrossRef] [PubMed]

12. Balachandran, Y.L.; Girija, S.; Selvakumar, R.; Tongpim, S.; Gutleb, A.C.; Suriyanarayanan, S. differently environment stable bio-silver nanoparticles: Study on their optical enhancing and antibacterial properties. PLoS ONE 2013, 8, e77043. [CrossRef] [PubMed]

13. Barbinta-Patrascu, M.E.; Constantin, M.; Badea, N.; Ungureanu, C.; Iordache, S.M.; Purcar, V.; Antohe, S. Tangerine-Generated Silver-Silica Bioactive Materials. Rom. J. Phys. 2019, 64, 701.

14. M'hiri, N.; Ioannou, I.; Ghoul, M.; Mihoubi Boudhrioua, N. Phytochemical characteristics of citrus peel and effect of conventional and nonconventional processing on phenolic compounds: A review. Food Rev. Int. 2017, 33, 587-619. [CrossRef]

15. Alu'datt, M.H.; Rababah, T.; Alhamad, M.N.; Gammoh, S.; Al-Mahasneh, M.A.; Tranchant, C.C.; Rawshdeh, M. Chapter 15-Pharmaceutical, nutraceutical and therapeutic properties of selected wild medicinal plants: Thyme, spearmint, and rosemary. In Therapeutic, Probiotic, and Unconventional Foods; Academic Press: Cambridge, MA, USA, 2018; pp. 275-290.

16. Bahrami-Teimoori, B.; Nikparast, Y.; Hojatianfar, M.; Akhlaghi, M.; Ghorbani, R.; Pourianfar, H.R. Characterisation and antifungal activity of silver nanoparticles biologically synthesised by Amaranthus retroflexus leaf extract. J. Exp. Nanosci. 2017, 12, 129-139. [CrossRef]

17. Barbinta-Patrascu, M.E.; Bunghez, I.R.; Iordache, S.M.; Badea, N.; Fierascu, R.C.; Ion, R.M. Antioxidant properties of biohybrids based on liposomes and sage silver nanoparticles. J. Nanosci. Nanotechnol. 2013, 13, 2051-2060. [CrossRef] [PubMed]

18. Ruano, P.; Delgado, L.L.; Picco, S.; Villegas, L.; Tonelli, F.; Aguilera Merlo, M.E.; Rigau, J.; Diaz, D.; Masuelli, M. Extraction and characterization of pectins from peels of criolla oranges (Citrus sinensis): Experimental reviews. In Pectins-Extraction, Purification, Characterization and Applications; IntechOpen: London, UK, 2019; pp. 1-44.

19. Barbinta-Patrascu, M.E. Biohybrids based on DNA and bio-inspired lipid membranes: Design and characterization. Optoelectron. Adv. Mater. Rapid Commun. 2019, 13, 546-550.

20. Barbinta-Patrascu, M.E.; Badea, N.; Tुugulea, L.; Giurginca, M.; Meghea, A. Oxidative stress simulation on artificial membranes—chemiluminescent studies. Rev. Chim. 2008, 59, 834-837.

21. Ansari, M.A.; Khan, H.M.; Khan, A.A.; Malik, A.; Sultan, A.; Shahid, M.; Shujatullah, F.; Azam, A. Evaluation of antibacterial activity of silver nanoparticles magainst MSSA and MSRA on isolates from skin infections. Bio. Med. 2011, 3, 141-146.

22. NCCLS M7-A6. Methods for Dilution Antimicrobial Susceptibility Test for Bacteria that Grow Aerobically, 6th ed.; Clinical and Laboratory Standards Institute: Wayne, PA, USA, 2003; ISBN 1-56235-486-4.

23. Hugo, W.B.; Russel, A.D. Pharmaceutical Microbiology, 6th ed.; Blackwell Science: London, UK, 1998; pp. 248-253.

24. Valgas, C.; De Souza, S.M.; Smânia, E.F.A.; Smânia, A., Jr. Screening methods to determine antibacterial activity of natural products. Braz. J. Microbiol. 2007, 38, 369-380. [CrossRef] 
25. Barbinta-Patrascu, M.E.; Ungureanu, C.; Iordache, S.M.; Iordache, A.M.; Bunghez, I.R.; Ghiurea, M.; Badea, N.; Fierascu, R.C.; Stamatin, I. Eco-designed biohybrids based on liposomes, mint—nanosilver and carbon nanotubes for antioxidant and antimicrobial coating. Mat. Sci. Eng. C 2014, 39, 177-185. [CrossRef] [PubMed]

26. Rajendran, R.; Balakumar, C.; Kalaivani, J.; Sivakumar, R. Dyeability and antimicrobial properties of cotton fabrics finished with Punica granatum extracts. J. Text. Appar. Technol. Manag. 2011, 7, 1-12.

27. Grecu, M.; Novac, G.; Ionita, D.; Ungureanu, C. Incorporation of tobramycin biomimetic in hydroxyapatite coating on CoCrMo alloy and its antimicrobial activity. Rev. Chim. 2011, 62, 352-356.

28. Beggs, C.B.; Noakes, C.J.; Sleigh, P.A.; Fletcher, L.A.; Kerr, K.G. Methodology for determining the susceptibility of airborne microorganisms to irradiation by an upper-room UVGI system. J. Aerosol. Sci. 2006, 37, 885-902. [CrossRef]

29. Wilfinger, W.W.; Mackey, K.; Chomczynski, P. Effect of $\mathrm{pH}$ and Ionic Strength on the Spectrophotometric Assessment of Nucleic Acid Purity. BioTechniques 1997, 22, 474-481. [CrossRef]

30. Kaijanen, L.; Paakkunainen, M.; Pietarinen, S.; Jernström, E.; Reinikainen, S.-P. Ultraviolet detection of monosaccharides: Multiple wavelength strategy to evaluate results after capillary zone electrophoretic separation. Int. J. Electrochem. Sci. 2015, 10, 2950-2961.

31. Wang, F.; Ma, Y.; Liu, Y.; Cui, Z.; Ying, X.; Zhang, F.; Linhardt, R.J. A simple strategy for the separation and purification of water-soluble polysaccharides from the fresh Spirulina platensis. Sep. Sci. Technol. 2017, 52, 456-466. [CrossRef]

32. Barbinta-Patrascu, M.E.; Badea, N.; Ungureanu, C.; Ispas, A. Photophysical aspects regarding the effects of Paeonia officinalis flower extract on DNA molecule labelled with methylene blue. Optoelectron. Adv. Mat. Rapid Commun. 2019, 13, 131-135.

33. Coates, J. Interpretation of Infrared Spectra, a Practical Approach. In Encyclopedia of Analytical Chemistry; Meyers, R.A., Ed.; John Wiley \& Sons Ltd.: Chichester, UK, 2000.

34. Kanmani, P.; Dhivya, E.; Aravind, J.; Kumaresan, K. Extraction and analysis of pectin from citrus peels: Augmenting the yield from citrus limon using statistical experimental design. Iran. J. Energy Environ. 2014, 5, 303-312. [CrossRef]

35. Mébarki, M.; Hachem, K.; Faugeron-Girard, C.; Mezemaze, R.H.; Kaid-Harche, M. Extraction and analysis of the parietal polysaccharides of acorn pericarps from Quercus trees. Polimeros 2019, 29, 3. [CrossRef]

36. Vedhanayagama, M.; Nidhinb, M.; Duraipandya, N.; Naresha, N.D.; Jaganathana, G.; Ranganathana, M.; Kirana, M.S.; Narayanc, S.; Naira, B.U.; Sreeram, K.J. Role of nanoparticle size in self-assemble processes of collagen for tissue engineering application. Int. J. Biol. Macromol. 2017, 99, 655-664. [CrossRef] [PubMed]

37. Giosafatto, C.V.L.; Sabbah, M.; Al-Asmar, A.; Esposito, M.; Sanchez, A.; Santana, R.V.; Cammarota, M.; Mariniello, L.; Di Pierro, P.; Porta, R. Effect of mesoporous silica nanoparticles on glycerol-plasticized anionic and cationic polysaccharide edible films. Coatings 2019, 9, 172. [CrossRef]

38. Khorrami, S.; Zarrabi, A.; Khaleghi, M.; Danaei, M.; Mozafari, M.R. Selective cytotoxicity of green synthesized silver nanoparticles against the MCF-7 tumor cell line and their enhanced antioxidant and antimicrobial properties. Int. J. Nanomed. 2018, 13, 8013-8024. [CrossRef] [PubMed]

39. Ajitha, B.; Reddy, Y.A.K.; Reddy, P.S. Green synthesis and characterization of silver nanoparticles using Lantana camara leaf extract. Mater. Sci. Eng. C 2015, 49, 373-381. [CrossRef]

40. Barbinta-Patrascu, M.E.; Badea, N.; Ungureanu, C.; Constantin, M.; Pirvu, C.; Rau, I. Silver-based biohybrids "green" synthesized from Chelidonium majus L. Opt. Mat. 2016, 56, 94-99. [CrossRef]

41. Shankar, H.; Karthiga, P.; Swarnalatha, K.; Rajkuma, K. Green synthesis of silver nanoparticles using Capsicum frutescence and its intensified activity against E. coli. Resour. Effic. Technol. 2017, 3, 303-308. [CrossRef]

42. Raut, R.W.; Lakkakula, J.R.; Kolekar, N.S.; Mendhulkar, V.D.; Kashid, S.B. Phytosynthesis of silver nanoparticle using Gliricidia Sepium. Curr. Nanosci. 2009, 5, 117-122.

43. Ávila-Morales, G.; Montes de Oca-Vásquez, G.; Alvarado-Marchena, L.; Pereira-Reyes, R.; Hernández-Miranda, M.; Gonzalez-Paz, R.; Vega-Baudrit, J.R. Biosynthesis of Silver Nanoparticles Using Mint Leaf Extract (Mentha piperita) and Their Antibacterial Activity. Adv. Sci. Eng. Med. 2017, 9, 1-10.

44. Jauregui-Gomez, D.; Bermejo-Gallardo, O.M.; Moreno-Medrano, E.M.; Perez-Garcia, M.G.; Ceja, I.; Soto, V.; Carvajal-Ramos, F.; Gutierrez-Becerra, A. Freeze-drying storage method based on pectin for gold nanoparticles. Nanomater. Nanotechnol. 2017, 7, 1-6. [CrossRef] 
45. Chicea, D. Nanoparticles and nanoparticle aggregates sizing by DLS and AFM. Optoelectron. Adv. Mat. Rapid Commun. 2010, 4, 1310-1315.

46. Chicea, D. Using AFM topography measurements in nanoparticle sizing. Rom. Rep. Phys. 2014, 66, 778-787.

47. Minzanova, S.T.; Mironov, V.F.; Arkhipova, D.M.; Khabibullina, A.V.; Mironova, L.G.; Zakirova, Y.M.; Milyukov, V.A. Biological activity and pharmacological application of pectic polysaccharides: A review. Polymers 2018, 10, 1407. [CrossRef] [PubMed]

48. Ro, Y.K.; Kim, H.; Jang, S.B.; Lee, H.J.; Chakma, S.; Jeong, J.H.; Lee, J. Antioxidative activity of pectin and its stabilizing effect on retinyl palmitate. Korean J. Physiol. Pharmacol. 2013, 17, 197-201. [CrossRef] [PubMed]

49. Pallavicini, P.; Arciola, C.R.; Bertoglio, F.; Curtosi, S.; Dacarro, G.; D'Agostino, A.; Ferrari, F.; Merli, D.; Milanese, C.; Rossi, S.; et al. Silver nanoparticles synthesized and coated with pectin: An ideal compromise for antibacterial and anti-biofilm action combined with wound-healing properties. J. Colloid Interface Sci. 2017, 498, 271-281. [CrossRef] [PubMed]

50. Hileuskayaa, K.; Ladutskab, A.; Kulikouskaya, V.; Kraskouski, A.; Novik, G.; Kozerozhets, I.; Kozlovskiy, A.; Agabekov, V. 'Green' approach for obtaining stable pectin-capped silver nanoparticles: Physico-chemical characterization and antibacterial activity. Colloids Surf. A 2020, 585, 124-141. [CrossRef]

51. Ferreyra Maillard, A.P.V.; Dalmasso, P.R.; Lopez de Mishima, B.A.; Hollmann, A. Interaction of green silver nanoparticles with model membranes: Possible role in the antibacterial activity. Colloids Surf. B Biointerfaces 2018, 171, 320-326. [CrossRef]

52. Písaříková, B.; Kráčmar, S.; Herzig, I. Amino acid contents and biological value of protein in various amaranth species. Czech J. Anim. Sci. 2005, 50, 169-174. [CrossRef]

53. Hutton, C.A.; Southwood, T.J.; Turner, J.J. Inhibitors of lysine biosynthesis as antibacterial agents. Mini Rev. Med. Chem. 2003, 3, 115-127. [CrossRef]

(C) 2020 by the authors. Licensee MDPI, Basel, Switzerland. This article is an open access article distributed under the terms and conditions of the Creative Commons Attribution (CC BY) license (http://creativecommons.org/licenses/by/4.0/). 